\title{
Aerosol particle size distribution in the stratosphere retrieved from SCIAMACHY limb measurements
}

\author{
Elizaveta Malinina $^{1}$, Alexei Rozanov ${ }^{1}$, Vladimir Rozanov ${ }^{1}$, Patricia Liebing ${ }^{1, a}$, Heinrich Bovensmann ${ }^{1}$, and \\ John P. Burrows ${ }^{1}$ \\ ${ }^{1}$ Institute of Environmental Physics (IUP), University of Bremen, Bremen, Germany \\ ${ }^{a}$ now at: Leiden Observatory, University of Leiden, Leiden, the Netherlands
}

Correspondence: Elizaveta Malinina (malininaep@iup.physik.uni-bremen.de)

Received: 27 October 2017 - Discussion started: 6 November 2017

Revised: 9 March 2018 - Accepted: 14 March 2018 - Published: 12 April 2018

\begin{abstract}
Information about aerosols in the Earth's atmosphere is of a great importance in the scientific community. While tropospheric aerosol influences the radiative balance of the troposphere and affects human health, stratospheric aerosol plays an important role in atmospheric chemistry and climate change. In particular, information about the amount and distribution of stratospheric aerosols is required to initialize climate models, as well as validate aerosol microphysics models and investigate geoengineering. In addition, good knowledge of stratospheric aerosol loading is needed to increase the retrieval accuracy of key trace gases (e.g. ozone or water vapour) when interpreting remote sensing measurements of the scattered solar light. The most commonly used characteristics to describe stratospheric aerosols are the aerosol extinction coefficient and Ångström coefficient. However, the use of particle size distribution parameters along with the aerosol number density is a more optimal approach. In this paper we present a new retrieval algorithm to obtain the particle size distribution of stratospheric aerosol from space-borne observations of the scattered solar light in the limb-viewing geometry. While the mode radius and width of the aerosol particle size distribution are retrieved, the aerosol particle number density profile remains unchanged. The latter is justified by a lower sensitivity of the limb-scattering measurements to changes in this parameter. To our knowledge this is the first data set providing two parameters of the particle size distribution of stratospheric aerosol from space-borne measurements of scattered solar light. Typically, the mode radius and $w$ can be retrieved with an uncertainty of less than $20 \%$. The algorithm was successfully applied to the tropical region $\left(20^{\circ} \mathrm{N}-20^{\circ} \mathrm{S}\right)$ for 10 years
\end{abstract}

(2002-2012) of SCIAMACHY observations in limb-viewing geometry, establishing a unique data set. Analysis of this new climatology for the particle size distribution parameters showed clear increases in the mode radius after the tropical volcanic eruptions, whereas no distinct behaviour of the absolute distribution width could be identified. A tape recorder, which describes the time lag as the perturbation propagates to higher altitudes, was identified for both parameters after the volcanic eruptions. A quasi-biannual oscillation (QBO) pattern at upper altitudes $(28-32 \mathrm{~km})$ is prominent in the anomalies of the analysed parameters. A comparison of the aerosol effective radii derived from SCIAMACHY and SAGE II data was performed. The average difference is found to be around $30 \%$ at the lower altitudes, decreasing with increasing height to almost zero around $30 \mathrm{~km}$. The data sample available for the comparison is, however, relatively small.

\section{Introduction}

Stratospheric aerosols are of a great interest for researchers because of their impact on the climate. The radiative budget of the Earth is altered by stratospheric aerosol, which scatters electromagnetic radiation in the atmosphere. A large amount of aerosol emitted by volcanic eruptions significantly changes the radiative forcing affecting global temperatures. For example, the super-colossal Tambora eruption in 1815 is claimed to have caused "the year without a summer" in 1816. The more recent colossal eruption of Mount Pinatubo in 1991 caused a surface temperature cooling of a few tenths of a kelvin (Robock and Mao, 1995). According to Solomon et al. 
(2011), smaller volcanic eruptions also noticeably affect the global temperature. Another important role of aerosols is their ability to act as condensation nuclei for polar stratospheric clouds (PSCs), which provide surface for heterogeneous chlorine activation and denitrification processes, thus increasing ozone depletion (Solomon, 1999).

Accurate information about stratospheric aerosols is important for different research fields. For example, stratospheric aerosol parameters are needed for modelling the processes related to the stratosphere, including aerosol microphysics model validation. Modellers require stratospheric aerosol climatologies as initial conditions for climate model simulations and predictions (e.g. Solomon et al., 2011; Fyfe et al., 2013). Fyfe et al. (2013) concluded that it is not only temperature that is affected by the volcanic eruptions but also precipitation, sea level pressure, and wind speed change in response to the changing aerosol load. All the abovementioned data are not only needed for improving global climate models but also required for the investigation of geoengineering. In addition, accurate knowledge of the stratospheric aerosol loading is essential to improve trace gases retrievals from measurements of the scattered solar light (e.g. Rozanov et al., 2011; Arosio et al., 2017).

As summarized by Kremser et al. (2016), stratospheric aerosols are commonly described as spherical droplets composed of a mixture of sulfuric acid $\left(\mathrm{H}_{2} \mathrm{SO}_{4}\right)$ and water $\left(\mathrm{H}_{2} \mathrm{O}\right)$. They may also be comprised of meteoric dust as well as other nonsulfate material. The most important sources of stratospheric aerosols are carbonyl sulfide (OCS) and sulfur dioxide $\left(\mathrm{SO}_{2}\right)$, which are oxidized to sulfuric acid. Short-lived $\mathrm{SO}_{2}$ is mostly injected directly into the lower stratosphere by large volcanic eruptions, while OCS, the longest-lived sulfur gas, which has mostly marine origin, is transported from the troposphere into the stratosphere by convection in the tropics. Aerosol composition in the stratosphere is controlled by the Brewer-Dobson circulation, as well as by chemistry and microphysics during aerosol formation, growth, and removal through sedimentation. Although some studies show increased $\mathrm{SO}_{2}$ from fossil fuel combustion transported to the lower stratosphere via the Asian monsoon (Randel et al., 2010), stratospheric aerosol precursors have predominantly natural sources (e.g. volcanic eruptions and OCS emissions from the ocean) (Kremser et al., 2016). Biomass burning, which is mostly of anthropogenic origin, can also lead to the enhanced stratospheric aerosols by emitting $\mathrm{SO}_{2}, \mathrm{OCS}$, and black carbon. Multiple instruments registered the increase in the measured quantities during the Australian "Black Saturday" bushfires (e.g Siddaway and Petelina, 2011).

One of the most commonly used characteristics to describe stratospheric aerosols is their extinction coefficient. Although it was employed in many previous studies dealing with space-borne measurements in UV-visible-IR spectral range (Ovigneur et al., 2011; Taha et al., 2011; Ernst, 2013; Brinkhoff et al., 2015; Dörner, 2015; von Savigny et al., 2015; Rieger et al., 2015, 2018), the usage of this parame- ter is associated with several issues. First the extinction coefficient is wavelength dependent and this dependence is determined by the composition of the aerosol droplets and their particle size distribution. Second, while a direct evaluation of the aerosol extinction can be done for occultation measurements, for limb measurements this parameter is dependent on the assumed particle size distribution parameters.

In contrast to the extinction coefficient, the retrieval presented in this paper characterizes not only the amount of the stratospheric aerosol but also its particle size distribution as it is widely done in in situ measurements (Deshler et al., 2003). Most commonly, mode radius, distribution width, and the particle number density are used to describe the particle size distribution of stratospheric aerosols. These parameters are, however, challenging to retrieve. Additionally, some information about the particle size distribution can be obtained from the Ångström coefficient, which is determined by the wavelength dependence of the aerosol extinction coefficient. However, the Ångström coefficient cannot be uniquely transformed into particle size distribution parameters. Generally, different combinations of the mode radius and distribution width may result in the same value of the Angström coefficient. Furthermore, for each particular particle size distribution the resulting Ångström coefficient usually depends on the wavelength range.

Highly vertically resolved information on stratospheric aerosols is provided by in situ balloon-borne and aircraft measurements, as well as by remote sensing measurements from ground-based lidars (Deshler et al., 2003). However, these measurements are quite sparse, and therefore satellite observations are commonly used to obtain knowledge about the global behaviour of stratospheric aerosols. Spaceborne measurements of the stratospheric aerosols started in the late 1970s with SAM (Stratospheric Aerosol Measurement), SAM II, SAGE (Stratospheric Aerosol and Gas Experiment) and SAGE II instruments (Yue et al., 1989). The latter was one of the most distinguished instruments of this era; it operated from 1984 to 2005 and used the solar occultation technique. The current v7.0 SAGE II product provides the aerosol extinction at four wavelengths and some information on particle size distribution parameters (more detailed in Sect. 5). At the beginning of the 2000s several spaceborne instruments of a newer generation using stellar occultation and limb measurement techniques were launched. SCIAMACHY (Scanning Imaging Absorption Spectrometer for Atmospheric CHartographY) was one of these instruments operated on the Envisat satellite from 2002 to 2012. SCIAMACHY had three main measurement modes: nadir, solar/lunar occultation, and limb scattering. Other instruments on board Envisat providing stratospheric aerosol information were Global Ozone Monitoring by Occultation of Stars (GOMOS) and the Michelson Interferometer for Passive Atmospheric Sounding (MIPAS). GOMOS made measurements using the stellar occultation technique and provided aerosol extinction coefficient (Vanhellemont et al., 
2016), while the MIPAS instrument measured limb emission spectra (Fischer et al., 2008) and provided vertical profiles of $\mathrm{SO}_{2}$ and sulfate aerosol $\left(\mathrm{H}_{2} \mathrm{SO}_{4}\right)$ volume densities (Günther et al., 2018). OSIRIS (Optical Spectrograph and InfraRed Imager System), on board the Odin satellite, which was launched in 2001 and is still operating, measures scattered solar light in the limb-viewing geometry (Llewellyn et al., 2004). Using these data, aerosol extinction profiles and Ångström coefficient are retrieved (Bourassa et al., 2012; Rieger et al., 2014). The most recent instrument, which combines nadir and limb scattering measurements, is the Ozone Mapping Profiler Suite (OMPS) (Jaross et al., 2014). OMPS was launched by NASA at the end of 2011 and is still in operation. First results with respect to the retrievals of aerosol extinction coefficient from OMPS-LP (Limb Profiler) are presented in several publications (Taha et al., 2011; Arosio et al., 2017; Loughman et al., 2017). In addition, it is important to mention the space-based lidar CALIOP (Cloud-Aerosol Lidar with Orthogonal Polarization Lidar), which provides measurements of aerosol backscatter coefficient, which is afterwards converted to the aerosol extinction coefficient. Profiles of the aerosol extinction from CALIOP have the highest vertical resolution among the space-borne instruments (Vernier et al., 2011).

This paper has the following structure: in Sect. 2 the most essential information about the SCIAMACHY instrument and the retrieval method used in the study is presented. In Sect. 3 the sensitivity of the retrieval algorithm is investigated. Results of the SCIAMACHY data retrieval along with the discussion are presented in Sect. 4. In Sect. 5 retrieval results from SCIAMACHY are compared to the SAGE II particle size distribution product. Conclusions are given in Sect. 6.

\section{Instrument and applied algorithm}

\subsection{SCIAMACHY on Envisat}

SCIAMACHY was a joint German, Dutch, and Belgian contribution to Envisat (European Environmental Satellite) launched by the European Space Agency (ESA) on 1 March 2002 into a sun-synchronous orbit at $800 \mathrm{~km}$ altitude with a 10:00 descending node Equator-crossing time. SCIAMACHY provided data from August 2002 to April 2012, when the connection with the satellite was suddenly lost. The instrument operated in three observational modes: nadir, limb, and solar/lunar occultation. Measurements of the solar irradiance were provided on a daily basis. SCIAMACHY took measurements in eight spectral channels, which covered the spectral interval between 214 and $2386 \mathrm{~nm}$. Spectral resolution varied from 0.2 to $1.5 \mathrm{~nm}$ depending on the wavelength.

In this study, measurements taken in the limb-viewing geometry were used. In this geometry the instrument observed the atmosphere tangentially to the Earth's surface in the altitude range from about $3 \mathrm{~km}$ below the surface, i.e. when Earth's surface is still within the field of view of the instrument, and then scanning vertically up to about $100 \mathrm{~km}$. The measurements were performed with a vertical instantaneous geometrical field of view at the tangent point of $2.6 \mathrm{~km}$ and vertical sampling of $3.3 \mathrm{~km}$. The horizontal cross-track field of view was $110 \mathrm{~km}$. A horizontal scan with the total swath of about $960 \mathrm{~km}$ was performed during each observation sequence. The horizontal cross-track resolution was mainly determined by the integration time during the horizontal scan, usually reaching about $240 \mathrm{~km}$. For a typical limb measurement, the observed signal integrated by the instrument was read out four times per horizontal scan, which resulted in four independent limb radiance profiles obtained during a horizontal scan. The horizontal along-track resolution is estimated to be about $400 \mathrm{~km}$. Further information about the instrument can be found in Burrows et al. (1995), Bovensmann et al. (1999), and Gottwald and Bovensmann (2011).

The retrievals performed for this study were done using version 8 of the SCIAMACHY Level 1 data with calibration flags $1,2,4,5$, and 7 , i.e. the leakage current, pixelto-pixel gain, stray-light correction, wavelength calibration, and radiometric calibration, respectively. Level 1 data were provided by ESA.

\subsection{Aerosol parametrization}

A balance of the processes creating and removing the stratospheric aerosols as well as of those influencing the size of aerosol particles commonly results in a size distribution which is well described by a single- or multiple-mode lognormal shape (Hansen and Travis, 1974; Thomason et al., 1997; Deshler et al., 2003; Deshler, 2008; Rieger et al., 2014). For example, in some cases Deshler et al. (2003) use a bimodal particle size distribution to achieve the best approximation to their measurements from in situ optical particle counters (OPCs). However, this approach is not suitable for remote sensing instruments working in the limb or occultation geometry. This is because six independent pieces of information at each altitude level are needed to describe a bimodal log-normal particle size distribution, while measurements from space-borne instruments commonly provide two to three parameters per altitude level (Bingen et al., 2004a; Thomason et al., 2008; Rieger et al., 2014). Here, similar to other studies cited above, the distribution is considered to be unimodal and is described by

$\frac{\mathrm{d} n}{\mathrm{~d} r}=\frac{N}{\sqrt{2 \pi} \ln (\sigma) r} \exp \left(-\frac{\left(\ln \left(r_{g}\right)-\ln (r)\right)^{2}}{2 \ln ^{2}(\sigma)}\right)$,

where $N$ is the total number density of the aerosol particles, $r_{g}$ is the median radius, and $\ln (\sigma)$ is the standard deviation of the $\frac{\mathrm{d} \ln (n)}{\mathrm{d} \ln (r)}$ distribution. Though $r_{g}$ is directly used in the formula and indicates the maximum of $\frac{\mathrm{d} \ln (n)}{\operatorname{dn}(r)}$ distribution, we 
prefer to work with the mode radius $R_{\text {mod }}=r_{g} / \exp \left(\ln ^{2}(\sigma)\right)$, which determines the maximum of $\frac{\mathrm{d} n}{\mathrm{~d} r}$ distribution and, thus, is more evident for the interpretation of results. Furthermore, throughout this study a representation of the absolute distribution width by the standard deviation of the $\frac{\mathrm{d} n}{\mathrm{~d} r}$ distribution will be used:

$w=\sqrt{r_{g}^{2} \exp \left(\ln ^{2}(\sigma)\right)\left(\exp \left(\ln ^{2}(\sigma)\right)-1\right)}$.

For visual interpretation, $w$ is more convenient than $\sigma$, as the latter is defined relative to the $r_{g}$ parameter. In the following text $\sigma$ is used when describing retrieval settings, while $w$ is used when discussing the retrieval results.

\subsection{Algorithm description}

Unlike the algorithms aimed to retrieve aerosol particle size distribution parameters from the occultation measurements (e.g. Bingen et al., 2004a; Thomason et al., 2008), our algorithm does not include aerosol extinction retrieval as an intermediate step. Instead, the measured limb radiances at seven wavelengths are directly employed to obtain the parameters. The wavelengths are chosen outside the intervals near the spectral channel boundaries to avoid artifacts of the optical system. In order to reduce the measurement noise the sun-normalized radiances are averaged in the following intervals: $\lambda_{1}=750 \pm 2 \mathrm{~nm}, \lambda_{2}=807 \pm 2 \mathrm{~nm}, \lambda_{3}=870 \pm 2 \mathrm{~nm}$, $\lambda_{4}=1090 \pm 2 \mathrm{~nm}, \quad \lambda_{5}=1235 \pm 20 \mathrm{~nm}, \quad \lambda_{6}=1300 \pm 6 \mathrm{~nm}$, and $\lambda_{7}=1530 \pm 30 \mathrm{~nm}$. The wavelengths below $750 \mathrm{~nm}$ are not considered because of a lower sensitivity to aerosols, and those above $1530 \mathrm{~nm}$ are rejected because of an insufficient signal-to-noise ratio. The intervals are chosen to avoid absorption signatures of other atmospheric constituents, minimizing uncertainties caused by incorrect absorber profiles knowledge. Limb radiances are normalized by the measured solar irradiance spectrum $\left(\boldsymbol{I}_{\mathrm{sol}}\right)$.

Both forward modelling and the retrieval are performed with the software package SCIATRAN-3.8 (Rozanov et al., 2014). The retrieval approach employs an iterative regularized inversion technique similar to that described by Rodgers (2000) to solve the inverse problem. In this approach the inversion of the linearized radiative transfer equation is required, which is formulated as

$\boldsymbol{y}-\boldsymbol{y}_{0}=\mathbf{K} \hat{\boldsymbol{x}}+\epsilon$,

where $\boldsymbol{y}$ is the measurement vector, whose components $[\boldsymbol{y}]_{m}=\ln \left(\frac{\boldsymbol{I}_{\text {meas }}\left(\lambda_{j}, h_{k}\right)}{\boldsymbol{I}_{\text {sol }}\left(\lambda_{j}\right)}\right)$ are the logarithms of the normalized limb radiances at all selected wavelengths $(\lambda)$ and tangent heights $(h)$. Here, index $m$ is defined as $m=(k-1) N_{\lambda}+j$, where $N_{\lambda}$ is the total number of wavelengths, $k$ runs over selected $h$, and $j$ runs over selected $\lambda$. Components of the vector $\boldsymbol{y}_{0}$ are given by $\left[\boldsymbol{y}_{0}\right]_{m}=\ln \left(\frac{\boldsymbol{I}_{\mathrm{mod}}\left(\lambda_{j}, h_{k}\right)}{\boldsymbol{I}_{\mathrm{sol}}\left(\lambda_{j}\right)}\right)$, where $\boldsymbol{I}_{\text {mod }}\left(\lambda_{j}, h_{k}\right)$ are modelled limb spectra at wavelength $\lambda_{j}$ and tangent height $h_{k}$. State vector $\hat{\boldsymbol{x}}$ contains relative deviations of the retrieved atmospheric parameters, $\boldsymbol{x}$, from their initial values, $\boldsymbol{x}_{0}$, e.g. $[\hat{\boldsymbol{x}}]_{i}=\frac{[\boldsymbol{x}]_{i}-\left[\boldsymbol{x}_{0}\right]_{i}}{\left[\boldsymbol{x}_{0}\right]_{i}}$ is the $i$ th component of the vector $\hat{\boldsymbol{x}}$. $[\mathbf{K}]_{m, i}=\left.\frac{\partial[\boldsymbol{y}]_{m}}{\partial[\boldsymbol{x}]_{i}}\right|_{\boldsymbol{x}=\boldsymbol{x}_{0}}$ defines components of the weighting function matrix (Jacobian matrix). All kinds of errors are denoted by $\epsilon$. The solution of the linear inverse problem given by Eq. (3) can be found according to Rodgers (2000) as

$\hat{\boldsymbol{x}}=\left(\mathbf{K}^{T} \mathbf{S}_{y}^{-1} \mathbf{K}+\mathbf{S}_{a}^{-1}\right)^{-1} \mathbf{K}^{T} \mathbf{S}_{y}^{-1}\left(\boldsymbol{y}-\boldsymbol{y}_{0}\right)$,

where $\mathbf{S}_{a}$ represents the a priori covariance matrix, and $\mathbf{S}_{y}$ is the noise covariance matrix.

Taking into consideration the non-linearity of the inverse problem, an iterative approach is implemented. Here, we do not follow the maximum a posteriori probability (MAP) approach suggested by Rodgers (2000). As the inverse problem is strongly non-linear, the use of a reasonable a priori covariance in the MAP approach results in a diverging solution, while the a priori variance which results in a stable solution strongly constrains it to the initial guess. To overcome this issue the weighted regularized inversion similar to zerothorder Tikhonov method is used in this study. Thereby, the weight of the a priori information is decreased by replacing the initial state vector $\boldsymbol{x}_{0}$ at each iterative step by the state vector obtained at the previous iteration, $\boldsymbol{x}_{n}$. The variance of $\boldsymbol{x}_{n}$ is set to $1 \%$. This parameter was selected empirically to achieve a trade-off between the retrieval stability and sensitivity. Thus the solution at the $(n+1)$ step is given by

$\widetilde{\boldsymbol{x}}=\left(\mathbf{K}_{n}^{T} \mathbf{S}_{y}^{-1} \mathbf{K}_{n}+\mathbf{S}_{a}^{-1}\right)^{-1} \mathbf{K}_{n}^{T} \mathbf{S}_{y}^{-1}\left(\boldsymbol{y}-\boldsymbol{y}_{\boldsymbol{n}}\right)$,

where $[\widetilde{\boldsymbol{x}}]_{i}=\frac{\left[\boldsymbol{x}_{n+1}\right]_{i}-\left[\boldsymbol{x}_{n}\right]_{i}}{\left[\boldsymbol{x}_{n}\right]_{i}}$.

The iterative process stops when the maximum difference between the components of the solution vector at two subsequent iterative steps does not exceed $1 \%$, the relative change in the root mean square of the fit residuals at two subsequent iterations is less than 0.001 or the limit of 100 iterations is reached. Since a strict constraint is put on deviations from the a priori vector, there are typically $20-30$ iterations needed for the retrieval process to converge.

The noise covariance matrix is assumed to be diagonal - i.e. the errors are spectrally uncorrelated. The signal-tonoise ratio was estimated for each scan from SCIAMACHY measurements and varies from 65 to 5000 depending on the wavelength and tangent height. For each of the particle size distribution parameters, the diagonal elements of the a priori covariance matrix are set empirically to 0.01 , and the nondiagonal elements drop off exponentially with a correlation radius of $3.3 \mathrm{~km}$, while the elements describing the correlation between different parameters are chosen to be 0 .

At present, only the retrieval of $R_{\bmod }$ and $\sigma$ is performed, and from these parameters $w$ is calculated using Eq. (2). The particle number density, $N$, profile is selected in accordance with the ECSTRA model climatology for background 
aerosol loading conditions (Fussen and Bingen, 1999). $N$ is assumed to decrease exponentially from $15.2 \mathrm{~cm}^{-3}$ at $18 \mathrm{~km}$ to $0.5 \mathrm{~cm}^{-3}$ at $35 \mathrm{~km}$ and remains unchanged during the whole retrieval process. This is justified by a low sensitivity of the retrieval to this parameter (see Sect. 3 for details). The initial guess parameter values are arbitrarily chosen as $R_{\text {mod }}=0.11 \mu \mathrm{m}$ and $\sigma=1.37$. Scattering phase functions as well as extinction and scattering coefficients per particle are calculated using the Mie scattering theory. Aerosol parameters are defined from 12 to $46 \mathrm{~km}$, where the particles are assumed to be sulfate droplets $\left(75 \% \mathrm{H}_{2} \mathrm{SO}_{4}\right.$ and $25 \% \mathrm{H}_{2} \mathrm{O}$ ) with $0 \%$ relative humidity in the surrounding atmosphere. Below $12 \mathrm{~km}$ and above $46 \mathrm{~km}$ the aerosol number density is set to 0 . The refractive indices are taken from the OPAC database (Hess et al., 1998). Although the chosen representation of the aerosol composition might be inadequate below the tropopause and/or above $35 \mathrm{~km}$, it enables us to avoid jumps and unreasonable values at the lowermost and the uppermost retrieval altitudes and does not affect significantly the retrieval sensitivity region $(18-32 \mathrm{~km}$; see Sect. 3.2 for details).

The retrieval is performed for the tropical zone (from $20^{\circ} \mathrm{S}$ to $20^{\circ} \mathrm{N}$ ) in the altitude range from about 18 up to about $35 \mathrm{~km}$ (the actual altitudes depend on the latitude and season). The choice of the altitude range is justified by lower sensitivity below $18 \mathrm{~km}$ (Rieger et al., 2018) and higher biases due to stray light above $35 \mathrm{~km}$. To minimize the need for constraints and to avoid additional errors, e.g. related to altitude interpolation, the measurement grid is used for the retrieval. The exact levels of the measurement grid depend on time and latitude, but usually the grid ranges from about 0 to $100 \mathrm{~km}$ with a $3.3 \mathrm{~km}$ step. Outside the retrieval range, for the altitudes lower than the minimum retrieval height down to $12 \mathrm{~km}$, the initial guess profile scaled relative to the result at the lowermost retrieved altitude is used, while for the altitudes above the upper border up to $46 \mathrm{~km}$ no additional constrains are set. We focus our initial study in the tropics because the transport mechanisms here are less complicated, which makes the interpretation of the obtained results more straightforward. To extend the retrieval to the extratropical latitude bands, issues related to the scattering angles close to backward and forward scattering as well as large solar zenith angles need to be dealt with.

To reduce the sensitivity of the retrieval to the reflection properties of the underlying surface, effective spectral Lambertian albedo is concurrently retrieved based on the limb radiances at the same tangent heights where the aerosol particle size retrieval is performed. As will be shown further, at $35 \mathrm{~km}$ aerosol influence on the limb radiances is rather small; thus the information from this tangent altitude contributes mainly to the albedo retrieval, while other tangent altitudes are employed for the stability reason. The initial albedo guess is 0.5 for all wavelengths. As for the particle size parameters, albedo for different wavelengths is uncorrelated with the other parameters and with the albedo at the other wavelengths. Clouds below and within the field of view remain an issue, even with the albedo retrieval. Therefore, only completely cloud-free profiles (from $0 \mathrm{~km}$ ) are used in this work. For this research, instead of the standard SCODA cloud-filtering algorithm (Eichmann et al., 2016), a cloudfiltering algorithm based on a statistical approach was used (Liebing, 2016). The algorithm designed by Liebing (2016) is more preferable for use in aerosol retrievals, because the Eichmann et al. (2016) approach has the disadvantage of flagging the pixels with high aerosol loading (i.e. after the volcanic eruptions) as cloudy.

Atmospheric pressure and temperature background profiles are from ECMWF (European Centre for Medium-Range Weather Forecasts) operational analysis data for the specific date, time, and location of each SCIAMACHY limb measurement.

\section{Sensitivity studies}

\subsection{Model simulations}

In this section sensitivity of the limb radiances to the aerosol particle size distribution parameters is analysed by performing simulations with the radiative transfer model SCIATRAN. For this study the model was run for an observational geometry typical for the tropical region in the middle of July (a solar zenith angle of $41^{\circ}$ and solar azimuth angle of $141^{\circ}$ ). The extraterrestrial solar flux measured by SCIAMACHY for the chosen day was used. In the radiative transfer model, multiple scattering was taken into account and the albedo was set to 0 (representation of the ocean surface).

To understand the sensitivity of the retrieval to the different particle size distribution parameters, three sets of limb radiance simulations were performed. For each set, one of the particle size distribution parameters was varied, while the other two parameters were fixed. The modelled intensities for these simulation sets are presented in Fig. 1 at the tangent height of $25 \mathrm{~km}$. As the results at other tangent heights show similar behaviour, we analyse the sensitivity only at this arbitrarily chosen geometry. Natural logarithms of the simulated sun-normalized intensities for different values of the selected parameter (this representation corresponds to the way that intensities are treated by the retrieval algorithm) are shown as lines. The shaded areas represent the amplitude of the intensity variations resulting from variations in the other two parameters. In this study the following simulation sets were performed: the first set employed a fixed $\sigma=1.37$ and the same number density profile as used in the retrieval, while the $R_{\text {mod }}$ varied from 0.05 to $0.15 \mu \mathrm{m}$ (Fig. 1a). Another set of conditions (Fig. 1b) was simulated by changing $\sigma$ from 1.1 to 2.0 with the fixed $R_{\text {mod }}=0.08 \mu \mathrm{m}$ and the same number density as in previous simulation set. This resulted in the variation in $w$ from 0.008 to $0.13 \mu \mathrm{m}$. The last set of simulations (Fig. 1c) was made by scaling the whole number 

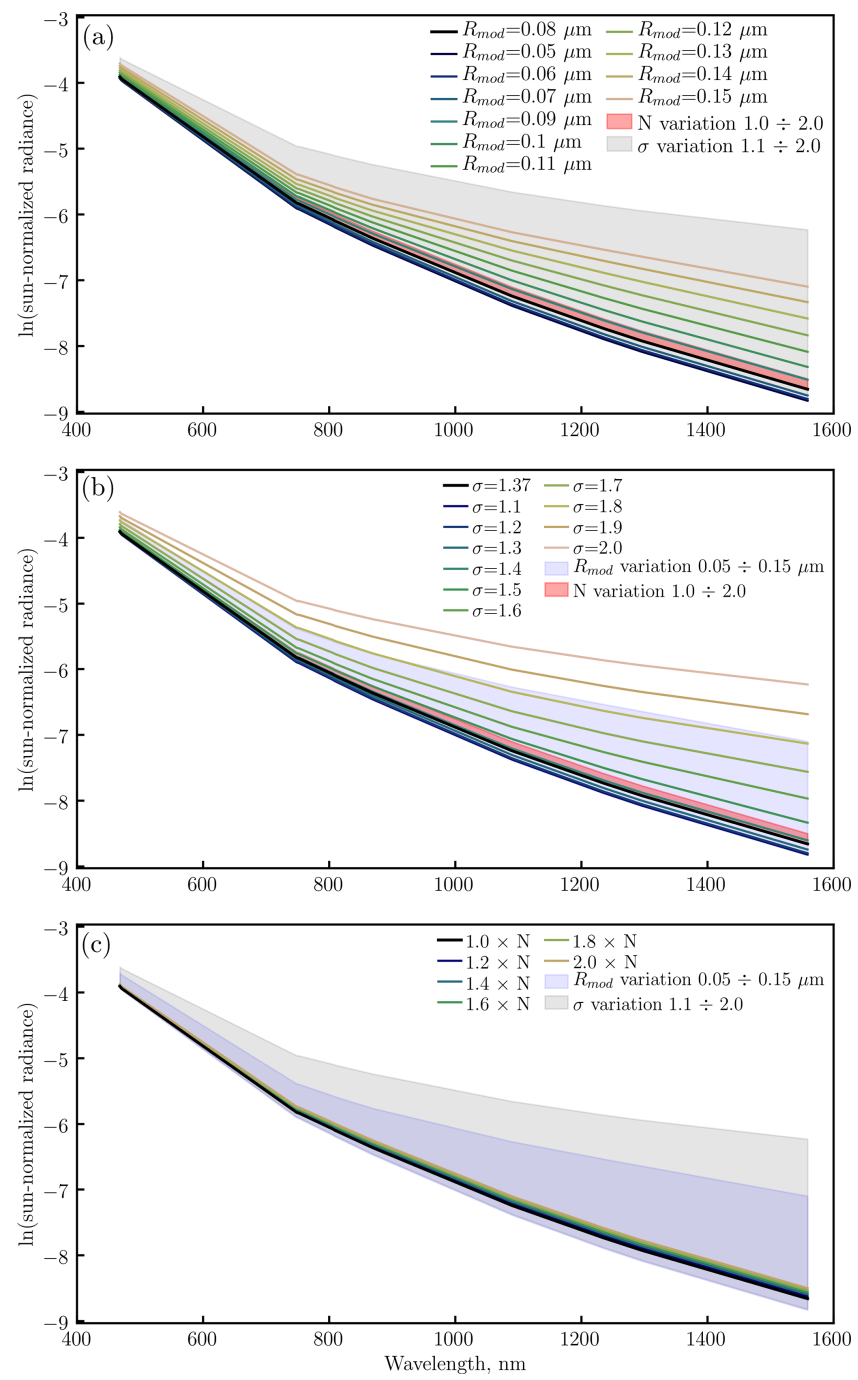

Figure 1. Logarithms of sun-normalized intensities spectra at a tangent height of $25 \mathrm{~km}$, modelled with different particle size distribution parameters. The black line represents the "standard" background conditions.

density profile by factors ranging from 1 to 2 , with the fixed $R_{\text {mod }}=0.08 \mu \mathrm{m}$ and $\sigma=1.37$. The parameter set with standard non-scaled $N$ profile with $R_{\text {mod }}=0.08 \mu \mathrm{m}$ and $\sigma=1.37$ was chosen as a reference, as this set of parameters is considered to be typical for a background (free of volcanic perturbations) atmosphere. We note that this investigation aimed to analyse a relative sensitivity of the observed limb radiance to the variations in different parameters and, thus, its results are not influenced much by their absolute values. Nevertheless, the considered amplitude of the parameter variations is in qualitative agreement with the reported variations in $R_{\bmod }$, $\sigma$, and $N$ in the stratosphere (Deshler et al., 2003).

Analysing Fig. 1 it is evident that variations in the limb radiance due to variations in the particle number density profile, $N$, are remarkably smaller than those due to variations

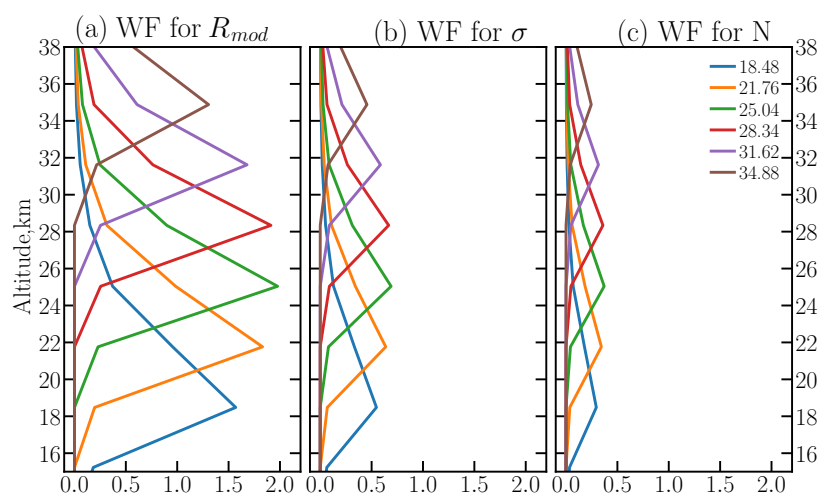

Figure 2. Relative logarithmic weighting functions at $\lambda_{7}=1530 \mathrm{~nm}$ in the retrieval height range for $R_{\bmod }(\mathbf{a}), \sigma(\mathbf{b})$, and particle number density $N$ (c). The different tangent heights are colour coded.

in $R_{\bmod }$ or $\sigma$ (or $w$ ). The variation in $N$ profile by a factor of 2 (or $200 \%$ ) results in a similar response in the limb radiance to the variation in $R_{\text {mod }}$ by $0.01 \mu \mathrm{m}(\approx 13 \%)$ or variation in $\sigma$ by $0.13(\approx 10 \%)$. This effect can be explained as follows: in a rough approximation the scattered solar radiance observed by a limb-viewing instrument is proportional to the product of $N$, scattering phase function $(p)$, and aerosol extinction cross section $\left(\alpha_{\text {aer }}\right)$ (see e.g. Chandrasekhar, 1960). Both $p$ and $\alpha_{\text {aer }}$ depend on $R_{\bmod }$ and $\sigma$. As the dependency of $p$ and $\alpha_{\text {aer }}$ on $R_{\bmod }$ and $\sigma$ is non-linear, these parameters contribute to the radiance stronger than $N$. The weaker dependence is also illustrated by much smaller weighting functions for $N$ than those for $R_{\bmod }$ or $\sigma$. The weighting functions ( $R_{\bmod }, \sigma$, and $N$ ) for each retrieved altitude are shown in Fig. 2. As the weighting functions (see Sect. 2.3) show the variations in the observed signal due to changes in the considered parameter, much smaller weighting functions of $N$ (Fig. 2c) mean much smaller contribution due to variations in the parameter in the measured signal. As a consequence, the variations in $N$ are neglected in the retrieval, and the altitudinal behaviour in the $N$ profile is considered to be constant with the time.

It is worth emphasizing again that the number density profile used in the above described retrieval is derived from the ECSTRA climatology for background aerosol loading conditions (see Sect. 2.3). Even though we increase the uncertainty for the volcanic active periods, for the background period the errors are rather small because we use the profile which is expected to be close to reality. The magnitude of the errors in the retrieved $R_{\text {mod }}, \sigma$, and $w$ due to unknown $N$ is discussed in the next section.

\subsection{Characterization of the retrieval}

The effect of the unknown number density on the retrieved $R_{\text {mod }}$ and $\sigma$, as well as general retrieval characteristics, is discussed in this section.

To characterize the sensitivity of retrieval algorithms averaging kernels are commonly used. In general, this character- 
istic is specific to the measurement setup, algorithm implementation, and retrieval parameters settings. Averaging kernels for the limb scatter space-borne instruments in the relevant altitude region are distinctly peaked at the tangent altitudes, where a bulk of information is originating from. Their shape characterizes the vertical sensitivity and resolution of the measurement-retrieval system and provides information on the contribution of the a priori information to the retrieved profiles.

In Fig. 3 averaging kernels for both $R_{\text {mod }}$ (panel a) and $\sigma$ (panel b) are presented for typical tropical observation conditions. Since variations in the observational geometry (viewing angle and solar zenith angle) in the tropics are rather small, only one specific example for typical illumination and background conditions is presented here. At all altitudes in the retrieval range (in this case 18.5-34.9 km), except for the uppermost one, averaging kernels for both parameters have pronounced peaks at the measurement tangent altitudes, indicating that no significant smearing of the results in the vertical domain has occurred and optimal sensitivity of the retrieval is achieved for each tangent altitude. At the uppermost altitude $(34.9 \mathrm{~km})$ averaging kernels are clearly broader and the peak is much less distinct in comparison to the other altitudes. Such a shape of the averaging kernels at this altitude is evidence of a strong influence of the neighbouring altitude levels and partial loss of sensitivity.

As pointed out above, in the performed retrieval the relative deviations from the solution obtained at the previous iterative step are determined. The state vector variance is set to $1 \%$ of the parameter values resulting from the previous iteration. For this reason such widely used characteristics as the averaging kernel peak value, a posteriori covariance, and measurement response are meaningful only within one iterative step but not applicable to the full iterative process.

An additional assessment of the retrieval performance was done by simulating the limb radiance using perturbed values for the retrieved parameters and then performing the retrieval using synthetic data. For all retrieval runs the same settings as in the nominal retrieval process were used. Ideally, the retrieved values are expected to be the same as those used to simulate the radiances. To test the retrieval under different conditions, five scenarios were used. All scenarios were simulated for one observation geometry (viewing and solar zenith angles) typical for SCIAMACHY limb measurements in the tropical region. Detailed information on the selected scenarios is presented in Table 1 . Generally, the scenarios can be divided into three types depending on the perturbation of the particle size parameters. The first type includes "small", "background", and "volcanic" scenarios. The intensities for these scenarios were modelled using $R_{\text {mod }}$ and $\sigma$ as listed in Table 1 with the same $N$ profile, as assumed in the retrieval algorithm - i.e. only $R_{\bmod }$ and $\sigma$ were perturbed. The second type is represented by the "volcanic $(2 \mathrm{~N})$ " scenario, which was modelled with the same $R_{\bmod }$ and $\sigma$ as the "volcanic scenario", but the $N$ profile was multiplied by a

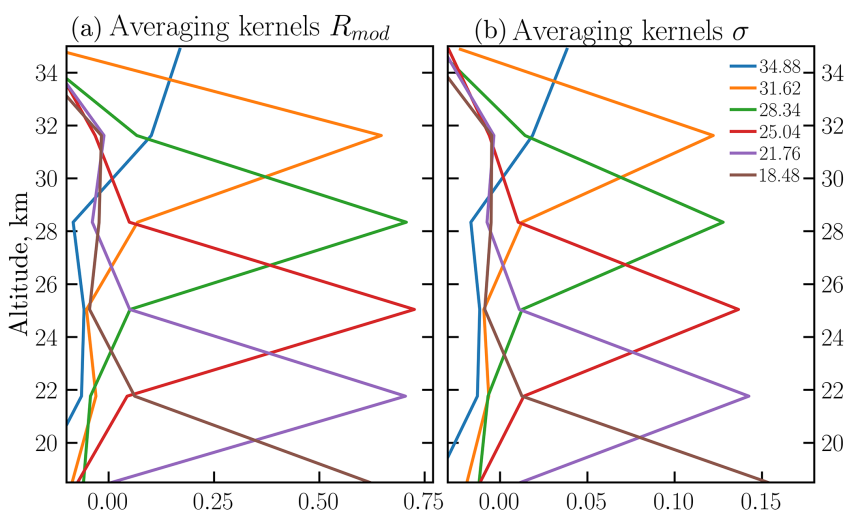

Figure 3. Averaging kernels for the aerosol particle size distribution parameters: $R_{\text {mod }}(\mathbf{a})$ and $\sigma$ (b). Results were obtained using the spectra modelled with perturbation of all three parameters. The different tangent heights are colour coded.

factor of 2 between 12 and $23 \mathrm{~km}$. The perturbation in the number density profile was performed only in the lower layers because significant changes in the aerosol loading due to volcanic eruptions during the SCIAMACHY lifetime were shown to reach maximum altitude of about $23 \mathrm{~km}$ (von Savigny et al., 2015). The third type is represented by the "unperturbed" scenario. For this scenario intensities were simulated with $R_{\bmod }=0.11 \mu \mathrm{m}, \sigma=1.37$, and the $N$ profile assumed in the retrieval, i.e. with the same parameter values as used to initialize the retrieval algorithm. All these values with slight adjustments were taken from Deshler (2008) and are expected to be close to the reality. As there is no reliable information on the altitudinal behaviour of $R_{\bmod }$ and $\sigma$, the values for those parameters are kept constant with the height. In all the scenarios modelled surface albedo was assumed to be 0.15 at all wavelengths. Gaussian noise has been added to all simulated limb radiances based on the signal-to-noise ratios estimated from SCIAMACHY measurements. To ensure reliable statistics, 100 independent noise sequences were generated.

Figure 4 presents the retrieved profiles of $R_{\text {mod }}$ (panel a) and their relative errors (panel $b$ ) for the above discussed scenarios. For $\sigma$, retrieved profiles and relative errors are plotted in Fig. 5. Solid lines in Figs. 4a and 5a refer to the median retrieved profiles for the scenario, and dashed lines represent true modelled conditions. In Figs. $4 \mathrm{~b}$ and $5 \mathrm{~b}$ solid lines show relative median errors of the retrieved profiles with respect to the true value. In both figures, shaded areas show \pm 1 standard deviation from the median value.

Analysis of Figs. 4 and 5 shows that the retrieval results using "unperturbed" profiles (brown lines) of $R_{\bmod }$ and $\sigma$ as well as the results for profiles with the perturbed $R_{\bmod }$ and $\sigma$ (cyan, blue, and green lines) are very close to the true values. The relative error is within $20 \%$ for $R_{\bmod }$ and within $5 \%$ for $\sigma$. Maxima of the absolute $(\epsilon=\mid$ retrieved - true $\mid)$ and relative errors for all scenarios and parameters are summarized in 
Table 1. Selected scenarios and associated maximum of absolute (relative) errors.

\begin{tabular}{|c|c|c|c|c|c|c|c|c|c|}
\hline \multirow[t]{2}{*}{ Name } & \multicolumn{4}{|c|}{ True } & \multirow[t]{2}{*}{ Colour* } & \multirow[t]{2}{*}{ Perturbation } & \multicolumn{3}{|c|}{ Max. } \\
\hline & $R_{\text {mod }}, \mu \mathrm{m}$ & $r_{g}, \mu \mathrm{m}$ & $\sigma$ & $w, \mu \mathrm{m}$ & & & $\epsilon_{R_{\mathrm{mod}}}, \mu \mathrm{m}$ & $\epsilon_{\sigma}$ & $\epsilon_{w}, \mu \mathrm{m}$ \\
\hline Small & 0.06 & 0.08 & 1.7 & 0.052 & cyan & $R_{\text {mod }}, \sigma$ & $0.01(19 \%)$ & $0.07(5 \%)$ & $0.001(2 \%)$ \\
\hline Background & 0.08 & 0.10 & 1.6 & 0.055 & blue & $R_{\text {mod }}, \sigma$ & $0.01(9 \%)$ & $0.04(2 \%)$ & $5 \times 10^{4}(1 \%)$ \\
\hline Unperturbed & 0.11 & 0.12 & 1.37 & 0.041 & brown & unpert. & $0.002(2 \%)$ & $0.009(1 \%)$ & $3 \times 10^{4}(1 \%)$ \\
\hline Volcanic & 0.20 & 0.21 & 1.2 & 0.039 & green & $R_{\text {mod }}, \sigma$ & $0.01(5 \%)$ & $0.04(3 \%)$ & $0.005(13 \%)$ \\
\hline Volcanic $(2 \mathrm{~N})$ & 0.20 & 0.21 & 1.2 & 0.039 & red & $R_{\mathrm{mod}}, \sigma, N$ & $0.04(19 \%)$ & $0.1(8 \%)$ & $0.015(40 \%)$ \\
\hline
\end{tabular}

* Colour of the lines in Figs. 4-6.

In the last three columns maximum absolute error for the profile is given by the number without brackets, while the maximum relative error is presented in brackets.

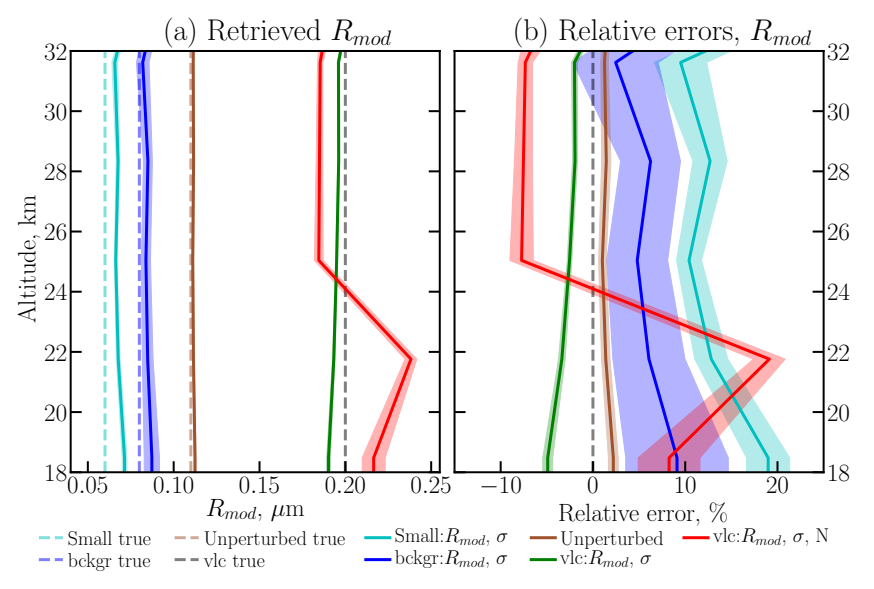

Figure 4. $R_{\text {mod }}$ profiles (a) and their relative errors (b) for a typical tropical observation geometry. The solid lines show the retrieval results, while the dashed lines represent the true values. The shaded areas stand for \pm 1 standard deviation. The scenarios used for the simulations are listed in Table 1.

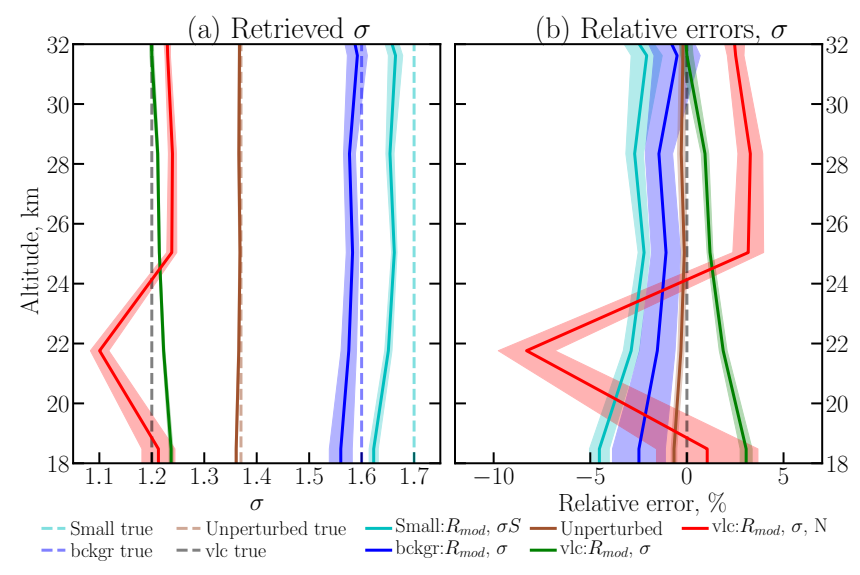

Figure 5. $\sigma$ profiles (a) and their relative errors (b) for a typical tropical observation geometry. The solid lines show the retrieval results, while the dashed lines represent the true values. The shaded areas stand for \pm 1 standard deviation. The scenarios used for the simulations are listed in Table 1.
Table 1. It is worth mentioning that the maximum deviation for the scenarios with unperturbed $N$ is about $\pm 0.01 \mu \mathrm{m}$ for $R_{\text {mod. }}$. For $\sigma$, the absolute error differs, but it does not exceed 0.07 . For the volcanic scenario with a perturbed $N$ profile it is obvious that a wrong number density assumption influences the retrieved profile, although this influence is rather small. The relative error for that case is less than $20 \%$ for $R_{\text {mod }}$ and less than $10 \%$ for $\sigma$, maximum absolute errors for $R_{\text {mod }}$ and $\sigma$ are respectively $0.04 \mu \mathrm{m}$ and 0.1 . The retrieval scenario with "unperturbed" particle size distribution parameters resulted in the profiles which differ less than $2 \%$ from the true values. This characterizes the retrieval error resulting from the measurement noise. The retrieved albedo varies from 0.11 to 0.23 depending on the scenario and the wavelength.

Referring to Sect. 2.2 it is important to remember that in this study we analyse $w$ as given by Eq. (2) rather than $\sigma$. Even though $\sigma$ as a parameter is widely used in the retrievals and in the climate models, it does not provide visually interpretable information about the width of the particle size distribution, because it is defined relative to $r_{g}$. For this reason we use $\sigma$ as a retrieval parameter, while $w$ is used in the interpretation and discussion of the retrieved results. For that reason it is important to assess retrieval uncertainties for $w$ as well.

In Fig. 6a, profiles of the absolute distribution width (solid lines), derived from the retrieved $R_{\bmod }$ and $\sigma$, for each scenario are depicted. As in Figs. 4 and 5, the dashed lines depict the true values. In of Fig. $6 \mathrm{~b}$ relative errors are plotted by solid lines. Shaded areas in Fig. 6a and b show the \pm standard deviation. Looking at Fig. 6, it is obvious that the retrieval errors from the distribution width for small (cyan lines), background (blue lines) and unperturbed (brown lines) scenarios are rather small: absolute errors (Table 1) are less than $0.001 \mu \mathrm{m}$, and relative errors are smaller than $2 \%$. In the volcanic case with unperturbed $N$ (green lines) differences are within $0.005 \mu \mathrm{m}$, which corresponds to $14 \%$. Conversely, for the volcanic scenario with perturbed $N$ (red lines), the derived $w$ deviates from the true value by up to $40 \%(0.015 \mu \mathrm{m})$. 
Table 2. Selected scenarios and associated maximum of absolute (relative) errors.

\begin{tabular}{|c|c|c|c|c|c|c|c|c|c|}
\hline \multirow[t]{2}{*}{ Name } & \multicolumn{4}{|c|}{ True } & \multirow[t]{2}{*}{ Colour* } & \multirow[t]{2}{*}{ Perturbation } & \multicolumn{3}{|c|}{ Max. } \\
\hline & $R_{\mathrm{mod}}, \mu \mathrm{m}$ & $r_{g}, \mu \mathrm{m}$ & $\sigma$ & $w, \mu \mathrm{m}$ & & & $\epsilon_{R_{\mathrm{mod}}}, \mu \mathrm{m}$ & $\epsilon_{\sigma}$ & $\epsilon_{w}, \mu \mathrm{m}$ \\
\hline Narrow & 0.20 & 0.21 & 1.2 & 0.039 & red & $R_{\mathrm{mod}}, \sigma, N$ & $0.04(19 \%)$ & $0.1(8 \%)$ & $0.015(40 \%)$ \\
\hline Wide & 0.20 & 0.21 & 1.27 & 0.053 & magenta & $R_{\mathrm{mod}}, \sigma, N$ & $0.05(24 \%)$ & $0.1(8 \%)$ & $0.012(23 \%)$ \\
\hline
\end{tabular}

* Colour of the lines in Figs. 7-8.

In the last 3 columns maximum absolute error for the profile is given by the number without brackets, while the maximum relative error is presented in brackets.

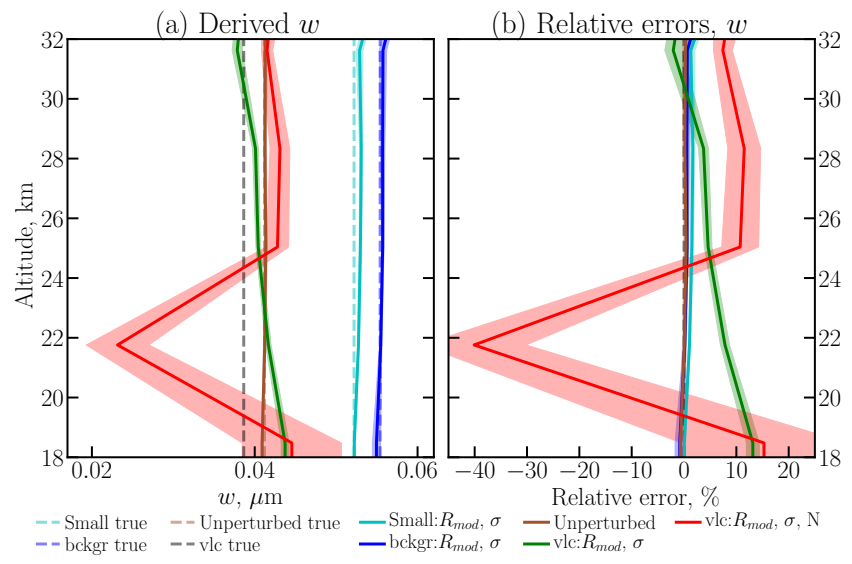

Figure 6. Absolute distribution width, $w$, profiles (a) and their relative errors (b) for a typical tropical observation geometry. The solid lines show the retrieval results, while the dashed lines represent the true values. The shaded areas stand for \pm 1 standard deviation. The scenarios used for the simulations are listed in Table 1.

Although the differences for $R_{\text {mod }}$ and $\sigma$ are comparably small, it is important to mention that, from all the modelled scenarios, $w$ for the volcanic scenarios is generally the smallest, and larger relative errors are often associated with the division by a small true value. To test this hypothesis another volcanic scenario with larger $w$ ("wide") was simulated ( $R_{\mathrm{mod}}=0.20 \mu \mathrm{m}, \sigma=1.27 ; N$ profile is perturbed by the factor of 2 in a layer between 12 and $23 \mathrm{~km}$ ) and run through the synthetic retrieval. The retrieved profiles of $R_{\text {mod }}, \sigma$, and absolute distribution width are shown in Fig. 7, where solid lines show the retrieved profiles and dashed lines represent true values. In red, the standard "narrow" volcanic scenario with perturbed $N$ is presented, whereas the magenta colours depict the "wide" scenario (see Table 2). Relative errors for these scenarios and parameters are presented in Fig. 8. From Figs. 7 and 8 it is clearly seen that even though the behaviour of $R_{\bmod }$ and $\sigma$ did not change significantly, and the absolute/relative errors are very similar for all three parameters, the maximum relative error for $w$ decreased to $23 \%$.

To summarize Sect. 3 it can be concluded that, for background conditions, the algorithm is capable of retrieving $R_{\text {mod }}$ with relative accuracy of better than $20 \%$ (absolute uncertainty of about $0.01 \mu \mathrm{m}$ ) and $\sigma$ better than $5 \%$ (absolute

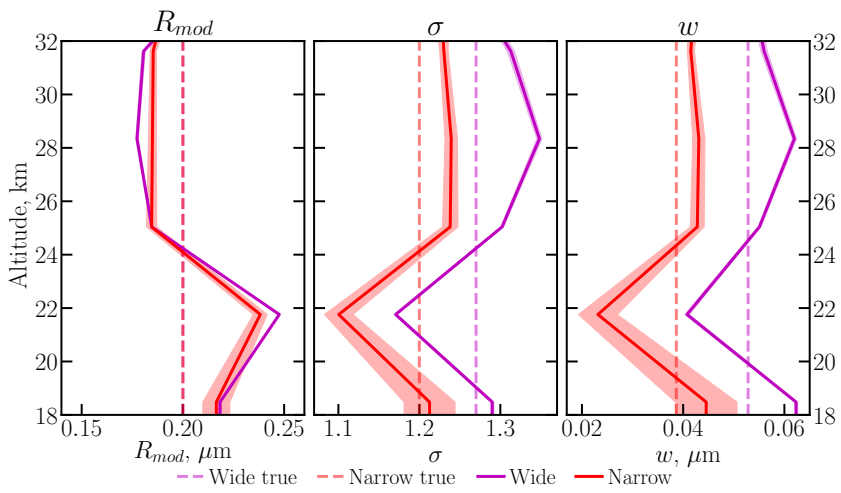

Figure 7. Retrieved profiles (solid lines) of $R_{\bmod }, \sigma$ and derived values of $w$ for the volcanic scenarios with perturbed $R_{\text {mod }}, \sigma, N$ for a typical tropical observation geometry. The dashed lines represent the true values. The shaded areas stand for \pm 1 standard deviation. The scenarios used for the simulations are listed in Table 2.

uncertainty less than 0.07). The relative accuracy of the derived $w$ is dependent on its absolute value and is about $2 \%$ $(0.001 \mu \mathrm{m})$ for background conditions. As $N$ is fixed in the retrieval, all uncertainties associated with this parameter are interpreted as changes in $R_{\bmod }$ and/or $\sigma$. Considering previous studies on stratospheric aerosol size distribution (Deshler et al., 2003; Bingen et al., 2004a, b; Deshler, 2008), we believe that for the period from 2002 to 2012 a variation in $N$ within a factor of 2 is a realistic assumption. Thus, possible retrieval errors after volcanic eruptions occurred during the SCIAMACHY observation period are estimated to be about 20-25\% for $R_{\text {mod }}$ and less than $10 \%$ for $\sigma$. For the volcanic scenarios the relative error for $w$ can reach up to $40 \%$, while the absolute error does not exceed $0.015 \mu \mathrm{m}$.

\section{Results and discussion}

In this section, first results of the retrieval of the aerosol particle size distribution parameters from SCIAMACHY limb observations are presented. As was mentioned above (see Sect. 2), the retrieval algorithm was applied to data for the tropical region and completely cloud-free (from $0 \mathrm{~km}$ ) scenes, resulting in 9727 profiles for the entire SCIAMACHY observation period. The cloud-filtering algorithm 


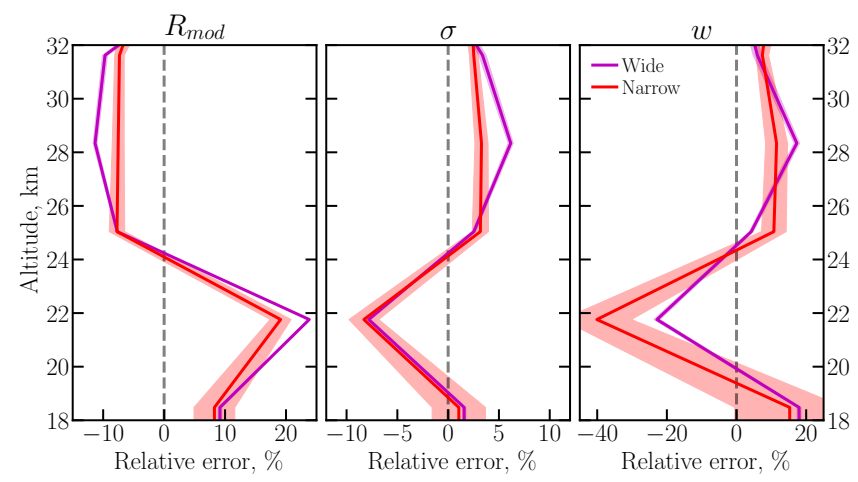

Figure 8. Relative errors for $R_{\bmod }, \sigma$ and derived $w$ for the volcanic scenarios with perturbed $R_{\bmod }, \sigma, N$ for a typical tropical observation geometry. The shaded areas stand for \pm 1 standard deviation. The scenarios used for the simulations are listed in Table 2 .

by Liebing (2016) used in this study employs a probability approach, which means that there is still a $10 \%$ chance in cloud or its fraction to influence the profile. Thus, to reject possible unreasonable results, post-retrieval filtering criteria were applied as follows: values with $R_{\bmod }<0.03 \mu \mathrm{m}$ were rejected, as they are laying outside the sensitivity range of the instrument, and aerosol extinction at $750 \mathrm{~nm}$ calculated using the retrieved particle size distribution parameters was not allowed to exceed $0.0015 \mathrm{~km}^{-1}$. A similar approach to filter the aerosol extinction at $750 \mathrm{~nm}$ was used to reject cloudy scenes in SCIAMACHY V1.4 aerosol extinction product (Rieger et al., 2018). Non-converged retrievals with 100 iterations $(4.6 \%$ of the whole amount of retrieved profiles) were also excluded. No additional filtering criteria were implemented. The maximum mode radius in the retrieved data set reached the value $R_{\bmod }=0.21 \mu \mathrm{m}$, and $\sigma$ varied from 1.02 to 2.9. All the values are considered to be realistic within the reported errors.

As the temporal sampling of the current product is not sufficient to analyse the volcanic plumes, monthly zonal $\left(20^{\circ} \mathrm{N}-\right.$ $20^{\circ} \mathrm{S}$ ) means were used to evaluate the overall state of the stratosphere during the SCIAMACHY observation period. These monthly averaged values of $R_{\bmod }$ and $w$ are presented in Figs. 9 and 10, respectively. Here, some obvious patterns such as the increase in the values after most of the volcanic eruptions (dashed lines) can be readily identified. In addition, there is a pronounced seasonality in both $R_{\bmod }$ and $w$. As the seasonal cycle of stratospheric aerosols has already been discussed by several authors (Hitchman et al., 1994; Bingen et al., 2004a), we focus our study on the analysis of the anomalies of the particle size distribution parameters. Anomalies or deseasonalized values for $R_{\bmod }$ and $w$, as shown in Figs. 11 and 12, respectively, were obtained by subtracting from each monthly mean value an average over all corresponding months in the whole observation period (e.g. the average value for all the Januaries of the 10 -year period was subtracted from each January monthly mean value in the observation period).

Analysing the anomalies for $R_{\text {mod }}$ presented in Fig. 11 it can be noticed that there is a distinct increase in $R_{\text {mod }}$ in the lower altitudes after most of the volcanic eruptions, except for the eruptions of Ruang and Reventador in late 2002 and Merapi in late 2010. For these tropical eruptions only a slight increase in $R_{\bmod }$ is observed. This may be related to a smaller amount of $\mathrm{SO}_{2}$ released during these eruptions (see database of the Smithsonian Institution, 2017, or Bingen et al., 2017). Another important feature is a periodic variation in $R_{\text {mod }}$ in the $28-32 \mathrm{~km}$ range, related to the quasibiennial oscillation (QBO). A similar QBO signature in the aerosol extinction coefficients retrieved from SCIAMACHY limb measurement at altitudes around $30 \mathrm{~km}$ was reported by Brinkhoff et al. (2015) and explained by the influence of the secondary meridional circulation. The QBO pattern is also seen in the anomalies of $w$ (Fig. 12). Volcanic eruptions influence aerosol $w$ in different ways. As for $R_{\text {mod }}$ there is an increase in $w$ after Tavurvur, Kasatochi, Sarychev, and Merapi eruptions, while there is a slight decrease in $w$ at some altitudes after Nabro eruption and no change in $w$ at all altitudes after the Manam eruption is observed.

Following the strong tropical eruptions (Manam, Tavurvur, Nabro) there is a well-defined increase in $R_{\text {mod }}$ shortly after the eruptions in the $18-21 \mathrm{~km}$ altitudes, while at higher altitudes $(22-26 \mathrm{~km})$ the volcanic perturbation is observed with a specific time lag. This is the so-called tape recorder effect, which is associated with the vertical transport of air masses in the tropical stratosphere. After strong mid-latitude eruptions (Sarychev, Kasatochi) the increase in $R_{\text {mod }}$ is less pronounced as compared to the tropical volcanoes, though there is a definite increase in $w$. There are two possible explanations for this effect. First, the initial and longer-term growth in particles is a result of the oxidation of $\mathrm{SO}_{2}$ to $\mathrm{H}_{2} \mathrm{SO}_{4}$, with chemical rates depending on the physical conditions at a given altitude and latitude. Second, during the transport of the air masses from the mid-latitudes to the tropics the aerosol particle size distribution is modified as a result of sedimentation of heavier particles with large radii. Unfortunately the justification for these hypotheses can be provided only after implementing the current algorithm for the extratropical latitudes and modelling the eruptions accounting for the aerosol microphysics, which is outside the scope of this study.

For a better understanding of the variations in the particle size distribution after different volcanic eruptions, we considered in more detail the temporal evolution of the aerosol particle size distributions at 18,22 and $25 \mathrm{~km}$ altitudes after the Manam and Tavurvur eruptions. This was done using the profiles retrieved from the individual measurements. The resulting distributions are presented in Fig. 13. For ease of comparison the distributions in the Manam series are plotted in the left column and for Tavurvur in the right column. As in Eq. (1), $N$ is a multiplicative factor of $\frac{\mathrm{d} n}{\mathrm{~d} r}, N=1 \mathrm{~cm}^{-3}$ was 


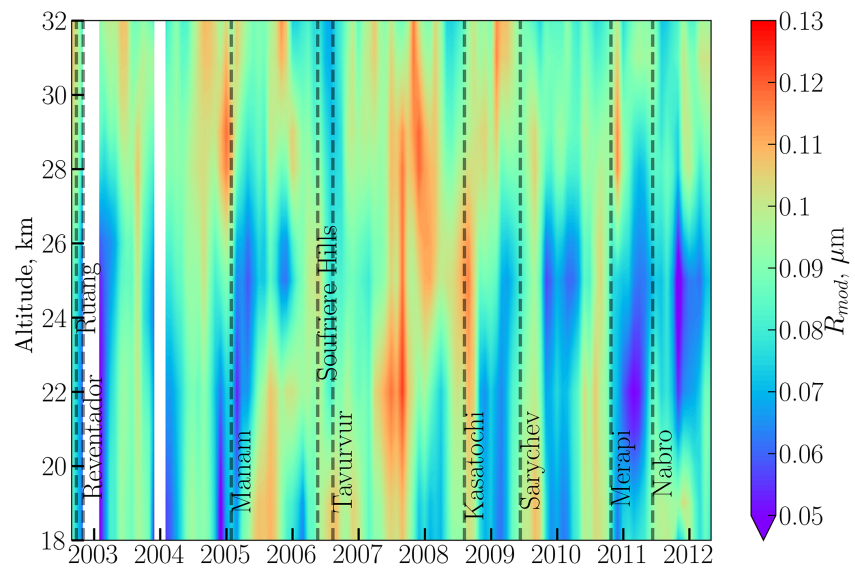

Figure 9. Monthly zonal mean values of $R_{\text {mod }}$ retrieved from SCIAMACHY limb data in the tropics $\left(20^{\circ} \mathrm{N}-20^{\circ} \mathrm{S}\right)$.

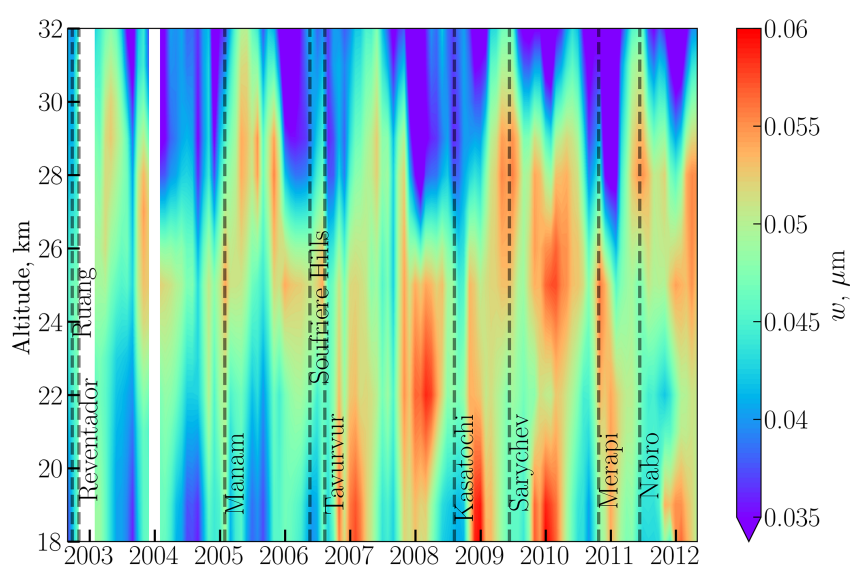

Figure 10. Monthly zonal mean values of $w$ as defined by Eq. (2) retrieved from SCIAMACHY limb data in the tropics $\left(20^{\circ} \mathrm{N}-20^{\circ} \mathrm{S}\right)$.

used for each altitude to make the Fig. 13 more descriptive. In each panel of Fig. 13 four distributions corresponding to different time lags before and after the eruptions obtained at similar latitudes $\left( \pm 2^{\circ}\right)$ are presented. There were four time slots chosen: before the eruption (green lines), in the first months after the eruption (red lines), more than half a year after the eruption (blue lines), and over a year after the eruption (cyan lines). The exact dates corresponding to the curves are presented in the legend below the panels.

As mentioned above, the Manam eruption was characterized by an increase in $R_{\text {mod }}$, but almost no change in $w$ after the eruption in comparison to the background conditions. This can be seen looking at the depicted distributions. At $18 \mathrm{~km}$ (upper left panel in Fig. 13) in the first months after the eruption (red line) the distribution shifts to the larger values in comparison to the distribution before the eruption (green line). Around 7 months after the eruption (blue line), distribution shifts to slightly smaller values, but its peak is still located at a distinctively larger radius value than for the back-

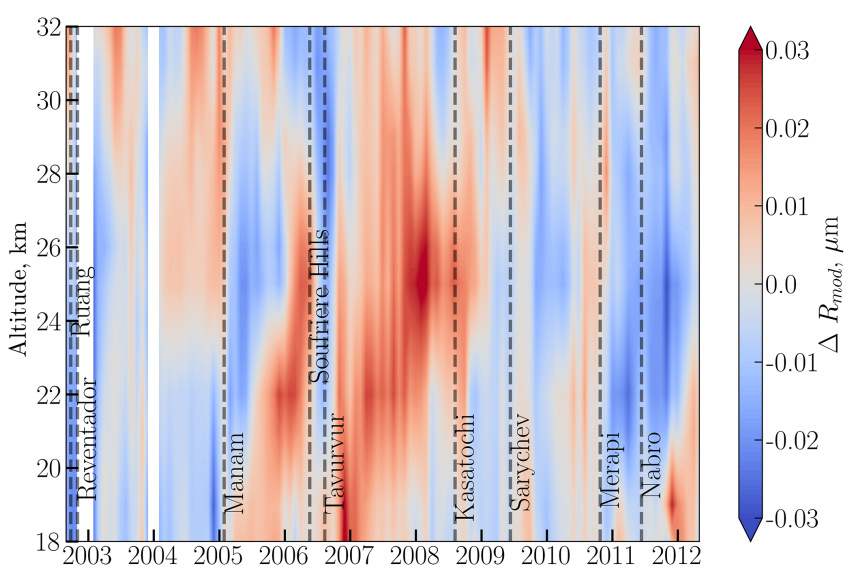

Figure 11. Deseasonalized time series (anomalies) of $R_{\bmod }$ retrieved from SCIAMACHY limb data in the tropics $\left(20^{\circ} \mathrm{N}-20^{\circ} \mathrm{S}\right)$.

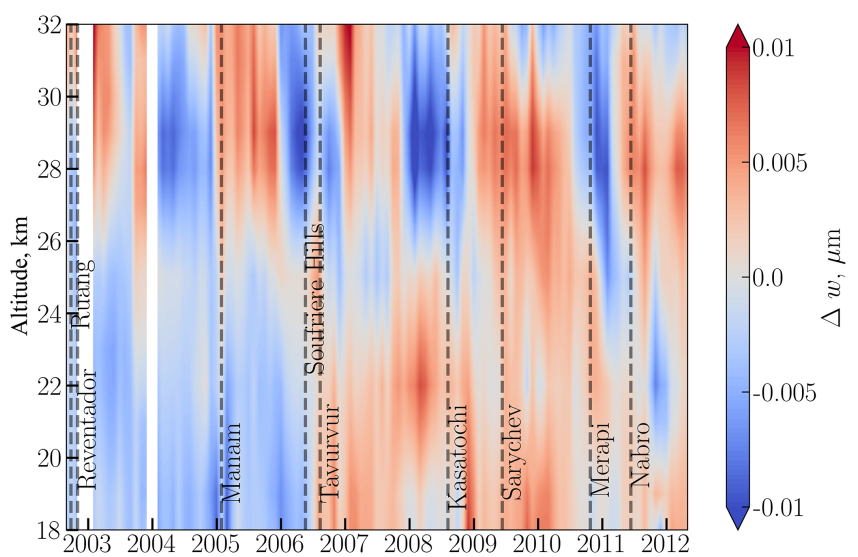

Figure 12. Deseasonalized time series (anomalies) of $w$ as defined by Eq. (2) retrieved from SCIAMACHY limb data in the tropics $\left(20^{\circ} \mathrm{N}-20^{\circ} \mathrm{S}\right)$.

ground distribution. At the end of March 2006, 14 months after the eruption (cyan line), the atmosphere at this altitude is "relaxed" and returns to a state close to that before the eruption, albeit with a slightly larger $R_{\text {mod }}$. This can be related to a weaker eruption of Manam at the end of February to the beginning of March 2006 (see database of Smithsonian Institution, 2017, or Bingen et al., 2017). It is worth mention that $w$ after the eruption (red, blue, and cyan lines) does not seem to change much in comparison to that of background conditions (green line), but it is obvious that the distribution before the eruption (green line) has a distinctively stronger relative contribution of larger particles than the one after the eruption. The distributions at $22 \mathrm{~km}$ (middle left panel in Fig. 13) before and shortly after the eruption look similar, with the perturbation to the particle size distribution shape being observed 7 and 14 months after eruption (blue and cyan lines). These time delays are attributed to the vertical transport velocity. For the same reason, the $25 \mathrm{~km}$ altitude (lower left panel in Fig. 13) distributions before the eruption, as well 

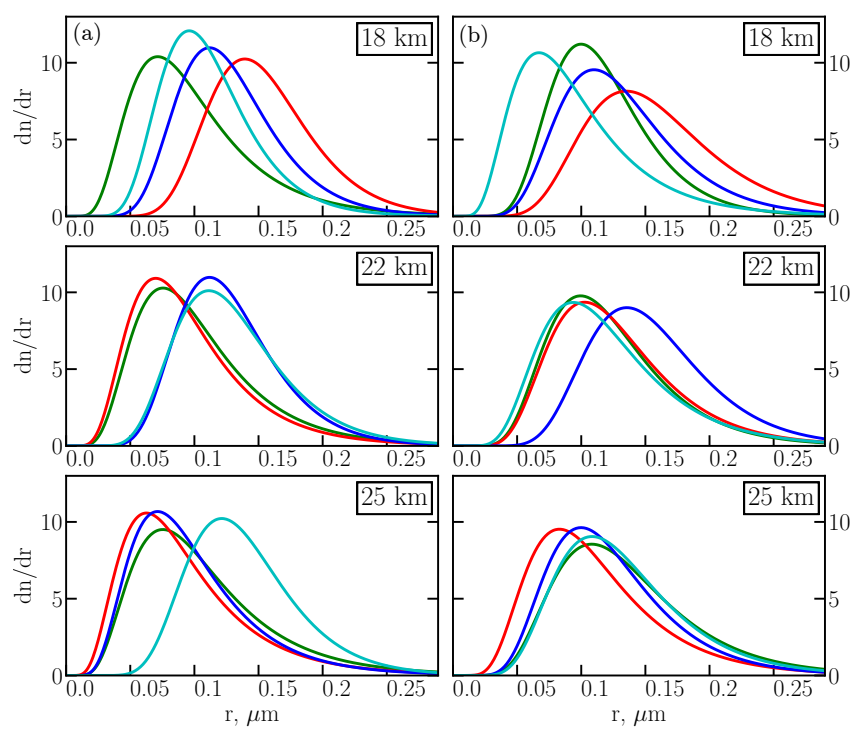

24 Jan 2005

22 Apr 2006

* Manam eruption (28 Jan 2005)

30 Mar 2005

9 Aug 2005

31 Mar 2006

* Tavurvur eruption (11 Aug 2006)

6 Sep 2007

5 Apr 2007

31 Nov 2007

Figure 13. Evolution of the aerosol particle size distribution at different altitudes $(18,22,25 \mathrm{~km})$ after the Manam (a) and Tavuvur (b) eruptions.

as 2 and 7 months after the eruption are similar to each other, but the one 14 months after the eruption is shifted to larger radii. For all distributions there is no noticeable change observed for $w$.

The temporal evolution of the aerosol particle size distribution after the Tavurvur eruption showed a different behaviour than that after Manam. At the lowermost retrieved altitude (18 km, upper right panel) aerosol particle size distribution shifts to the larger $R_{\text {mod }}$ and gets remarkably wider shortly after the eruption (red line). It appears that the stratospheric aerosol formed after the Tavurvur eruption overlapped with the one after the weaker Soufrière Hills eruption, which occurred several months before (see database of Smithsonian Institution, 2017, or Bingen et al., 2017). Although the Soufriere Hills eruption might have influenced the observed distributions, it is not possible to distinguish between these two eruptions and we will consider them as one event. About 8 months after the event, the distribution shifts to the smaller $R_{\text {mod }}$ and gets narrower. After 1 year (cyan line) the distribution returns almost to the same shape as before the eruption (green line), similar to the evolution after the Manam eruption. At $22 \mathrm{~km}$ (middle right panel of Fig. 13) the distribution responds as expected with the time lag of around half a year, and at $25 \mathrm{~km}$ the changes are most likely dominated by other processes and not significant in general.

Another remarkable event was the eruption of Nabro in the middle of June of 2011. As presented by Figs. 11 and 12 it was characterized by an increased $R_{\text {mod }}$ and a decreased $w$. The latter might be a result of significant volcanic activity preceding the Nabro eruption. Since this eruption occurred less than a year before the connection to ENVISAT was lost, we cannot fully track it.

\section{Comparison with SAGE II}

As mentioned in Sect. 1, SAGE II was one of the key instruments providing aerosol particle size information. Operating from 1984 to 2005, SAGE II has a 3-year overlap with SCIAMACHY, enabling us to use SAGE II as a comparison instrument in the assessment of SCIAMACHY aerosol particle size distribution product.

In this study the current version v7.0 of the SAGE II stratospheric aerosol data was used (Damadeo et al., 2013). This version reports extinction coefficients at multiple wavelengths along with the effective radius. Assuming the unimodal log-normal particle size distribution, effective radius can be related to the particle size distribution parameters as follows:

$r_{\text {eff }}=r_{g} \exp \left(2.5 \ln ^{2}(\sigma)\right)$.

As SAGE II is a solar occultation instrument, it provides 30 profiles (both sunrise and sunset events) per day. In contrast, SCIAMACHY is a limb scatter instrument, providing around 1400 measurements per day. However, only tropical and completely cloud-free profiles were used, so the resulting sampling was much sparser. Taking into consideration this sampling, fairly loose collocation criteria of $\pm 5^{\circ}$ latitude, $\pm 20^{\circ}$ longitude and $\pm 24 \mathrm{~h}$ were used for the comparison, resulting in 57 collocations during the 3 years of SCIAMACHY and SAGE II overlap. As SCIAMACHY vertical sampling is coarser than that of SAGE II, and SCIAMACHY retrievals were performed on a coarser altitude grid $(3.3 \mathrm{~km}$ compared to $0.5 \mathrm{~km}$ by SAGE II), SAGE II data were first smoothed to the SCIAMACHY vertical resolution and afterwards interpolated onto the SCIAMACHY vertical grid.

Mean relative difference between the $r_{\text {eff }}$ from SCIAMACHY and SAGE II is presented in Fig. 14. The relative difference is about $30 \%$ in the lower altitudes, decreasing with increasing height to less than $20 \%$ at $26 \mathrm{~km}$ and around $0 \%$ at $30 \mathrm{~km}$. As it can be seen in Fig. 15, where both collocated data sets are plotted versus time, the offset between SCIAMACHY (blue dots) and SAGE II (red dots) effective radii is constant with time, with SCIAMACHY being systematically lower at 18 and $21.3 \mathrm{~km}$. One of the possible reasons for the observed differences is the low sensitivity of SAGE II to the particles with radius smaller than $0.1 \mu \mathrm{m}$ (Thomason et al., 2008). In contrast, our investigations (not shown here) demonstrate that, for SCIAMACHY limb measurements, the sensitivity drops for particles smaller than $0.06 \mu \mathrm{m}$. This is explained by the differences in the measurement techniques. According to text books on radiative trans- 


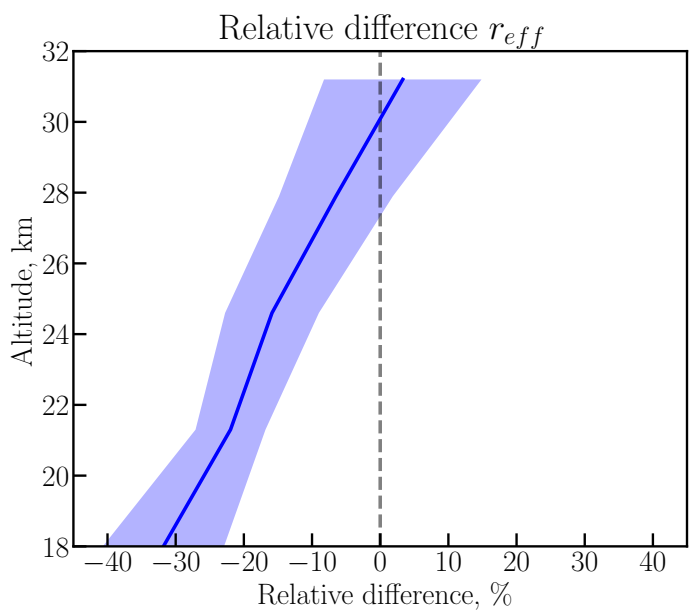

Figure 14. Mean relative difference ((SCIAMACHY - SAGE II) / SAGE II) between effective radii from collocated SCIAMACHY and SAGE II measurements.

fer, e.g. Chandrasekhar (1960), the signal observed by an occultation instrument is determined by the aerosol extinction coefficient, while for the measurements of the scattered solar light the product of the aerosol extinction coefficient and the scattering phase function is relevant. As the period from 2002 to 2005 was considered to be volcanically quiescent, smaller particles were dominant at the time, increasing the possible biases. However, for a more detailed evaluation of this aspect, a larger number of collocations need to be analysed. Possible reasons for the observed lopsided differences are still under investigation.

\section{Conclusions}

In this study a retrieval algorithm to obtain two parameters of the stratospheric aerosol particle size distribution $\left(R_{\bmod }\right.$ and $\sigma$ ) from SCIAMACHY limb measurements was presented. In this retrieval a fixed vertical distribution of the aerosol particle number density, $N$, is assumed, and $N$ is not retrieved. Wavelength dependent surface albedo is included in the retrieval. The algorithm uses the measurements of the scattered light at 7 wavelengths and a normalization to the extraterrestrial solar irradiance. Investigation of the averaging kernels showed a good sensitivity in the altitude range from 18 to $32 \mathrm{~km}$ for both retrieved parameters. Synthetic retrievals demonstrated that, using the presented algorithm for SCIAMACHY limb measurements, errors for $R_{\text {mod }}$ are typically in the range of $10-20 \%$ for the considered unperturbed $N$ profile (the reported absolute error is $0.01 \mu \mathrm{m}$ ). For $\sigma$, the errors are even smaller and within 5\% (absolute error value is less than 0.07 ). For a perturbed $N$ profile, errors increase to $20 \%$ for $R_{\bmod }$ and to $10 \%$ for $\sigma$. For easier interpretation of the retrieval results, the absolute distribution width, $w$, was used instead of $\sigma$. For $w$, the error is insignificant (less than 2\%)

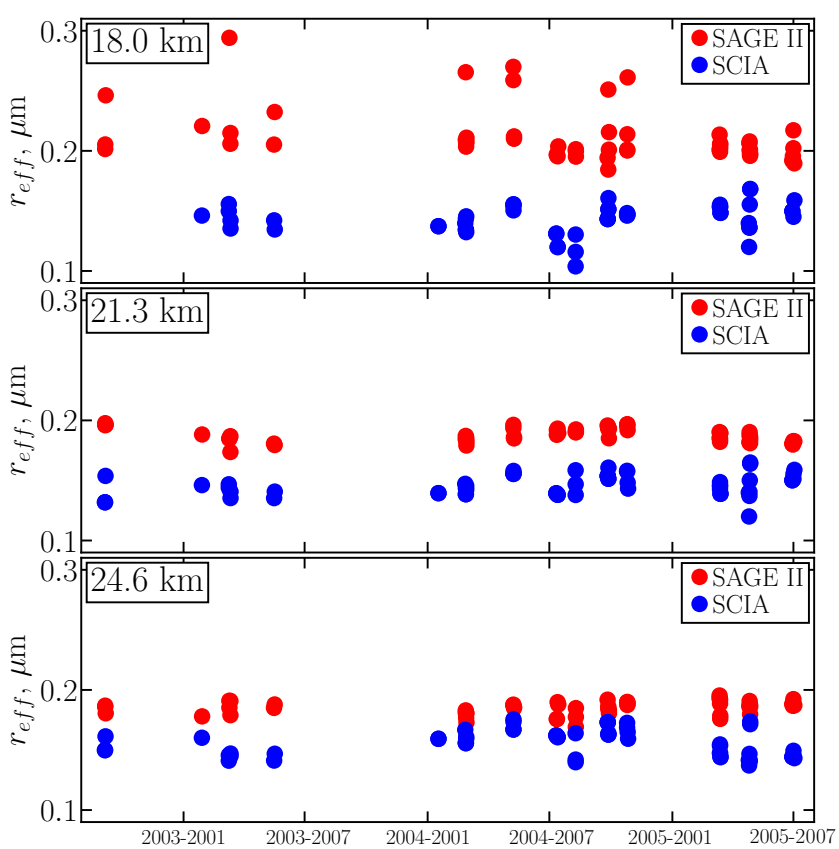

Figure 15. Effective radii from collocated SCIAMACHY and SAGE II measurements at $18,21.3$, and $24.6 \mathrm{~km}$ altitude.

for background conditions and can reach $40 \%$ after volcanic eruptions; however, it does not exceed $0.015 \mu \mathrm{m}$ in terms of the absolute differences. Implementation of this retrieval algorithm to SCIAMACHY measurements allowed us to generate the first, and for now unique, data set of two particle size distribution parameters from an instrument measuring scattered light in the limb-viewing geometry. Analysing the retrieval results, an increase in $R_{\text {mod }}$ in the altitude range from 18 to $25 \mathrm{~km}$ after the volcanic eruptions was identified, while $w$ after the volcanic eruptions did not show any distinct behaviour (can increase, decrease or remain unchanged). The tape recorder effect or delayed response of the parameters to the volcanic eruptions for higher altitudes was observed for both parameters. Variations in $28-32 \mathrm{~km}$ altitude range in both $R_{\text {mod }}$ and $w$ due to quasi-biannual oscillation (QBO) were identified. The retrieval results were compared to the SAGE II data and showed an agreement within $30 \%$ for effective radii in the lower altitudes, improving with increasing altitude to better than $10 \%$ above $25 \mathrm{~km}$. For all altitudes a systematic negative bias was observed.

Data availability. SCIAMACHY aerosol particle size distribution data are available after registration at http://www.iup.uni-bremen. de/scia-arc/. 
Competing interests. The authors declare that they have no conflict of interest.

Acknowledgements. This work was funded in part by the European Space Agency (ESA) through the SQWG and SPIN projects, the German Aerospace Center (DLR) through the SADOS project, and the German Federal Ministry of Education and Research (BMBF) through the ROMIC-ROSA project, as well as the University and state of Bremen. We thank ECMWF for providing pressure and temperature information. We also thank NASA for SAGE II data, which were downloaded from the NASA Langley Research Center EOSDIS Distributed Active Archive Center.

The article processing charges for this open-access publication were covered by the University of Bremen.

Edited by: Andrew Sayer

Reviewed by: two anonymous referees

\section{References}

Arosio, C., Rozanov, A., Malinina, E., Eichmann, K.-U., von Clarmann, T., and Burrows, J. P.: Retrieval of ozone profiles from OMPS limb scattering observations, Atmos. Meas. Tech. Discuss., https://doi.org/10.5194/amt-2017-301, in review, 2017.

Bingen, C., Fussen, D., and Vanhellemont, F.: A global climatology of stratospheric aerosol size distribution parameters derived from SAGE II data over the period 1984-2000: 1. Methodology and climatological observations, J. Geophys. Res.-Atmos., 109, D06201, https://doi.org/10.1029/2003JD003518, 2004a.

Bingen, C., Fussen, D., and Vanhellemont, F.: A global climatology of stratospheric aerosol size distribution parameters derived from SAGE II data over the period 1984-2000: 2. Reference data, J. Geophys. Res.-Atmos., 109, D06202, https://doi.org/10.1029/2003JD003511, 2004b.

Bingen, C., Robert, C. E., Stebel, K., Brühl, C., Schallock, J., Vanhellemont, F., Mateshvili, N., Höpfner, M., Trickl, T., Barnes, J. E., Jumelet, J., Vernier, J.-P., Popp, T., de Leeuw, G., and Pinnock, S.: Stratospheric aerosol data records for the climate change initiative: Development, validation and application to chemistry-climate modelling, Remote Sens. Environ., 203, 296321, 2017.

Bourassa, A. E., Rieger, L. A., Lloyd, N. D., and Degenstein, D. A.: Odin-OSIRIS stratospheric aerosol data product and SAGE III intercomparison, Atmos. Chem. Phys., 12, 605-614, https://doi.org/10.5194/acp-12-605-2012, 2012.

Bovensmann, H., Burrows, J., Buchwitz, M., Frerick, J., Noël, S., Rozanov, V., Chance, K., and Goede, A.: SCIAMACHY: Mission objectives and measurement modes, J. Atmos. Sci., 56, 127-150, 1999.

Brinkhoff, L. A., Rozanov, A., Hommel, R., von Savigny, C., Ernst, F., Bovensmann, H., and Burrows, J. P.: Ten-Year SCIAMACHY Stratospheric Aerosol Data Record: Signature of the Secondary Meridional Circulation Associated with the Quasi-Biennial Oscillation, in: Towards an Interdisciplinary Approach in Earth System Science, Springer, 49-58, https://doi.org/10.1007/978-3319-13865-7, 2015.
Burrows, J., Hölzle, E., Goede, A., Visser, H., and Fricke, W. SCIAMACHY - Scanning imaging absorption spectrometer for atmospheric chartography, Acta Astronaut., 35, 445-451, 1995.

Chandrasekhar, S.: Radiative Transfer, Dover Publications, NY, 393 pp., 1960.

Damadeo, R. P., Zawodny, J. M., Thomason, L. W., and Iyer, N.: SAGE version 7.0 algorithm: application to SAGE II, Atmos. Meas. Tech., 6, 3539-3561, https://doi.org/10.5194/amt-6-35392013, 2013.

Deshler, T.: A review of global stratospheric aerosol: Measurements, importance, life cycle, and local stratospheric aerosol, Atmos. Res., 90, 223-232, 2008.

Deshler, T., Hervig, M., Hofmann, D., Rosen, J., and Liley, J.: Thirty years of in situ stratospheric aerosol size distribution measurements from Laramie, Wyoming (41 N), using balloon-borne instruments, J. Geophys. Res.-Atmos., 108, 4167, https://doi.org/10.1029/2002JD002514, 2003.

Dörner, S.: Stratospheric aerosol extinction retrieved from SCIAMACHY measurements in limb geometry, PhD thesis, Universitätsbibliothek Mainz, Germany, 2015.

Eichmann, K.-U., Lelli, L., von Savigny, C., Sembhi, H., and Burrows, J. P.: Global cloud top height retrieval using SCIAMACHY limb spectra: model studies and first results, Atmos. Meas. Tech., 9, 793-815, https://doi.org/10.5194/amt-9-793-2016, 2016.

Ernst, F.: Stratospheric aerosol extinction profile retrievals from SCIAMACHY limb-scatter observations, $\mathrm{PhD}$ thesis, Staats-und Universitätsbibliothek Bremen, Germany, 2013.

Fischer, H., Birk, M., Blom, C., Carli, B., Carlotti, M., von Clarmann, T., Delbouille, L., Dudhia, A., Ehhalt, D., Endemann, M., Flaud, J. M., Gessner, R., Kleinert, A., Koopman, R., Langen, J., López-Puertas, M., Mosner, P., Nett, H., Oelhaf, H., Perron, G., Remedios, J., Ridolfi, M., Stiller, G., and Zander, R.: MIPAS: an instrument for atmospheric and climate research, Atmos. Chem. Phys., 8, 2151-2188, https://doi.org/10.5194/acp-8-21512008, 2008.

Fussen, D. and Bingen, C.: Volcanism dependent model for the extinction profile of stratospheric aerosols in the UV-visible range, Geophys. Res. Lett., 26, 703-706, 1999.

Fyfe, J., Salzen, K. v., Cole, J., Gillett, N., and Vernier, J.-P.: Surface response to stratospheric aerosol changes in a coupled atmosphere-ocean model, Geophys. Res. Lett., 40, 584-588, 2013.

Gottwald, M. and Bovensmann, H.: SCIAMACHY - Exploring the Changing Earth's Atmosphere, Springer, Dordrecht, the Netherlands, https://doi.org/10.1007/978-90-481-9896-2, 2011.

Günther, A., Höpfner, M., Sinnhuber, B.-M., Griessbach, S., Deshler, T., von Clarmann, T., and Stiller, G.: MIPAS observations of volcanic sulfate aerosol and sulfur dioxide in the stratosphere, Atmos. Chem. Phys., 18, 1217-1239, https://doi.org/10.5194/acp-18-1217-2018, 2018.

Hansen, J. E. and Travis, L. D.: Light scattering in planetary atmospheres, Space Sci. Rev., 16, 527-610, 1974.

Hess, M., Koepke, P., and Schult, I.: Optical properties of aerosols and clouds: The software package OPAC, B. Am. Meteorol. Soc., 79, 831-844, 1998.

Hitchman, M. H., McKay, M., and Trepte, C. R.: A climatology of stratospheric aerosol, J. Geophys. Res.-Atmos., 99, 20689 20700, 1994. 
Jaross, G., Bhartia, P. K., Chen, G., Kowitt, M., Haken, M., Chen, Z., Xu, P., Warner, J., and Kelly, T.: OMPS Limb Profiler instrument performance assessment, J. Geophys. Res.-Atmos., 119, 4399-4412, https://doi.org/10.1002/2013JD020482, 2014.

Kremser, S., Thomason, L. W., Hobe, M., Hermann, M., Deshler, T., Timmreck, C., Toohey, M., Stenke, A., Schwarz, J. P., Weigel, R., Fueglistaler, S., Prata, F. J., Vernier, J.-P., Schlager, H., Barnes, J. E., Antuña-Marrero, J.-C., Fairlie, D., Palm, M., Mahieu, E., Notholt, J., Rex, M., Bingen, C., Vanhellemont, F., Bourassa, A., Plane, J. M. C., Klocke, D., Carn, S. A., Clarisse, L., Trickl, T., Neely, R., James, A. D., Rieger, L., Wilson, J. C., and Meland, B.: Stratospheric aerosol - Observations, processes, and impact on climate, Rev. Geophys., 54, 278-335, 2016.

Liebing, P.: New Limb Cloud Detection Algorithm Theoretical Basis Document, available at: http://www.iup.uni-bremen. de/ patty/Limb_Clouds/atbd_limbcloudsV2.pdf (last access: 10 April 2018), 2016.

Llewellyn, E., Lloyd, N., Degenstein, D., Gattinger, R., Petelina, S., Bourassa, A., Wiensz, J., Ivanov, E., McDade, I., Solheim, B., McConnell, J. C., Haley, C. S., von Savigny, C., Sioris, C. E., McLinden, C. A., Griffioen, E., Kaminski, J., Evans, W. F. J., Puckrin, E., Strong, K., Wehrle, V., Hum, R. H., Kendall, D. J. W., Matsushita, J., Murtagh, D. P., Brohede, S., Stegman, J., Witt, G., Barnes, G., Payne, W. F., Piché, L., Smith, K., Warshaw, G., Deslauniers, D.-L., Marchand, P., Richardson, E. H., King, R. A., Wevers, I., McCreath, W., Kyrölä, E., Oikarinen, L., Leppelmeier, G. W., Auvinen, H., Mégie, G., Hauchecorne, A., Lefèvre, F., de La Nöe, J., Ricaud, P., Frisk, U., Sjoberg, F., von Schéele, F., and Nordh, L.: The OSIRIS instrument on the Odin spacecraft, Can. J. Phys., 82, 411-422, 2004.

Loughman, R., Bhartia, P. K., Chen, Z., Xu, P., Nyaku, E., and Taha, G.: The Ozone Mapping and Profiler Suite (OMPS) Limb Profiler (LP) Version 1 Aerosol Extinction Retrieval Algorithm: Theoretical Basis, Atmos. Meas. Tech. Discuss., https://doi.org/10.5194/amt-2017-299, in review, 2017.

Malinina, E., Rozanov, A., Vountas, M., and Burrows, J. P.: Stratospheric aerosol particle size distribution from SCIAMACHY limb data, Institute of Environmental Physics, University of Bremen, http://www.iup.uni-bremen.de/scia-arc/ (last access: 10 April 2018), 2017.

Ovigneur, B., Landgraf, J., Snel, R., and Aben, I.: Retrieval of stratospheric aerosol density profiles from SCIAMACHY limb radiance measurements in the $\mathrm{O}_{2}$ A-band, Atmos. Meas. Tech., 4, 2359-2373, https://doi.org/10.5194/amt-4-2359-2011, 2011.

Randel, W. J., Park, M., Emmons, L., Kinnison, D., Bernath, P., Walker, K. A., Boone, C., and Pumphrey, H.: Asian monsoon transport of pollution to the stratosphere, Science, 328, 611-613, 2010.

Rieger, L. A., Bourassa, A. E., and Degenstein, D. A.: Merging the OSIRIS and SAGE II stratospheric aerosol records, J. Geophys. Res.-Atmos., 120, 8890-8904, 2015.

Rieger, L. A., Bourassa, A. E., and Degenstein, D. A.: Stratospheric aerosol particle size information in Odin-OSIRIS limb scatter spectra, Atmos. Meas. Tech., 7, 507-522, https://doi.org/10.5194/amt-7-507-2014, 2014.

Rieger, L. A., Malinina, E. P., Rozanov, A. V., Burrows, J. P., Bourassa, A. E., and Degenstein, D. A.: A study of the approaches used to retrieve aerosol extinction, as applied to limb observations made by OSIRIS and SCIAMACHY, Atmos. Meas.
Tech. Discuss., https://doi.org/10.5194/amt-2017-446, in review, 2018.

Robock, A. and Mao, J.: The volcanic signal in surface temperature observations, J. Climate, 8, 1086-1103, 1995.

Rodgers, C. D.: Inverse methods for atmospheric sounding: theory and practice, vol. 2, World Scientific, Singapore, 2000.

Rozanov, A., Weigel, K., Bovensmann, H., Dhomse, S., Eichmann, K.-U., Kivi, R., Rozanov, V., Vömel, H., Weber, M., and Burrows, J. P.: Retrieval of water vapor vertical distributions in the upper troposphere and the lower stratosphere from SCIAMACHY limb measurements, Atmos. Meas. Tech., 4, 933-954, https://doi.org/10.5194/amt-4-933-2011, 2011.

Rozanov, V., Rozanov, A., Kokhanovsky, A., and Burrows, J.: Radiative transfer through terrestrial atmosphere and ocean: software package SCIATRAN, J. Quant. Spectrosc. Ra., 133, 13-71, 2014.

Siddaway, J. and Petelina, S.: Transport and evolution of the 2009 Australian Black Saturday bushfire smoke in the lower stratosphere observed by OSIRIS on Odin, J. Geophys. Res.-Atmos., 116, D06203, https://doi.org/10.1029/2010JD015162, 2011.

Smithsonian Institution: Global Volcanism Program Database, available at: http://volcano.si.edu/search_eruption.cfm (last access: 10 April 2018), 2017.

Solomon, S.: Stratospheric ozone depletion: A review of concepts and history, Rev. Geophys., 37, 275-316, 1999.

Solomon, S., Daniel, J. S., Neely, R. R., Vernier, J.-P., Dutton, E. G., and Thomason, L. W.: The persistently variable "background" stratospheric aerosol layer and global climate change, Science, 333, 866-870, 2011.

Taha, G., Rault, D. F., Loughman, R. P., Bourassa, A. E., and von Savigny, C.: SCIAMACHY stratospheric aerosol extinction profile retrieval using the OMPS/LP algorithm, Atmos. Meas. Tech., 4, 547-556, https://doi.org/10.5194/amt-4-547-2011, 2011.

Thomason, L. W., Poole, L. R., and Deshler, T.: A global climatology of stratospheric aerosol surface area density deduced from Stratospheric Aerosol and Gas Experiment II measurements: 1984-1994, J. Geophys. Res.-Atmos., 102, 8967-8976, 1997.

Thomason, L. W., Burton, S. P., Luo, B.-P., and Peter, T.: SAGE II measurements of stratospheric aerosol properties at non-volcanic levels, Atmos. Chem. Phys., 8, 983-995, https://doi.org/10.5194/acp-8-983-2008, 2008.

Vanhellemont, F., Mateshvili, N., Blanot, L., Robert, C. É., Bingen, C., Sofieva, V., Dalaudier, F., Tétard, C., Fussen, D., Dekemper, E., Kyrölä, E., Laine, M., Tamminen, J., and Zehner, C.: AerGOM, an improved algorithm for stratospheric aerosol extinction retrieval from GOMOS observations - Part 1: Algorithm description, Atmos. Meas. Tech., 9, 4687-4700, https://doi.org/10.5194/amt-9-4687-2016, 2016.

Vernier, J.-P., Thomason, L., and Kar, J.: CALIPSO detection of an Asian tropopause aerosol layer, Geophys. Res. Lett., 38, L07804, https://doi.org/10.1029/2010GL046614, 2011.

von Savigny, C., Ernst, F., Rozanov, A., Hommel, R., Eichmann, K.U., Rozanov, V., Burrows, J. P., and Thomason, L. W.: Improved stratospheric aerosol extinction profiles from SCIAMACHY: validation and sample results, Atmos. Meas. Tech., 8, 5223-5235, https://doi.org/10.5194/amt-8-5223-2015, 2015.

Yue, G. K., McCormick, M., Chu, W., Wang, P., and Osborn, M. Comparative studies of aerosol extinction measurements made 
by the SAM II and SAGE II satellite experiments, J. Geophys. Res.-Atmos., 94, 8412-8424, 1989. 